\title{
AVALIAÇÃO DE UM CICLO DE LIQUEFAÇÃO USANDO A TECNOLOGIA DE REFRIGERANTE MISTO PARA PLANTAS DE PEQUENA ESCALA DE GNL
}

\author{
Christian D. Tacuse Begazo e J. R. Simões-Moreira \\ Escola Politécnica da Universidade de São Paulo \\ Departamento de Engenharia Mecânica \\ SISEA - Lab. De Sistemas Energéticos Alternativos \\ Av. Prof. Mello Moraes, 2231, Cidade Universitária \\ 05508-900 - São Paulo - Brasil \\ E-mails: dtacuse@hotmail.com \\ jrsimoes@usp.br
}

\begin{abstract}
This work has the objective of analyzing the technology of mixed refrigerant cycle for obtaining liquefied natural gas (LNG). In that technology, the liquefied natural gas is obtained by means of cooling through a refrigeration cycle, whose fluid refrigerant is formed by a mixture of various components. The refrigeration cycle is used to cool the natural gas stream to cryogenic condition with the use of a heat exchanger. The determination of the optimal composition of this refrigerant mixture is very important for the correct and efficient operation of the plant. The thermodynamic model for the equilibrium phase calculation of the refrigerant mixture is based on the Law of Raoult, which is valid for ideal mixtures and solutions. Initially, the concepts of refrigerant mixture, composite curves and pinch point used in the implementation of the numerical solution were reviewed. The application of ideal-gas and ideal-solution models has influence on the results. Nevertheless, it produces good results as those obtained in the present work. The efficient operation of the cycle depends essentially of three key parameters, which are: refrigerant flow rate, the ratio of high to low pressures of the refrigerant cycle and the mixed refrigerant composition. The results indicated that the composition variation of the refrigerant changes significantly the shape of hot and cold composite curves in comparison to the modification in the pressure levels and the refrigerant flow rate of the refrigerant cycle. However, the process will operate only if a given set of values of those parameters satisfies a minimum temperature difference, or pinch point, between the hot and cold composite curves within the heat exchanger. Thus, the efficient operation of the refrigerant cycle requires the optimization of those three operational parameters.
\end{abstract}

Key-words: Liquefaction, small scale plants, mixed refrigerant, liquefied natural gas, pinch analysis.

Resumo. Este trabalho tem como objetivo analisar a tecnologia do ciclo refrigerante misto para obtenção de gás natural liquefeito (GNL). Nessa tecnologia, o GNL é obtido por meio do seu resfriamento através de um ciclo de refrigeração, cujo fluido refrigerante é formado por uma mistura de diversos componentes. $\mathrm{O}$ ciclo de refrigeração é usado para resfriar a corrente de gás natural até as condições criogênicas por meio de um trocador de calor. A determinação da composição ótima dessa mistura de refrigerantes é de suma importância para a correta e eficiente operação da planta. O modelo termodinâmico para o cálculo de equilíbrio de fases dos componentes da mistura refrigerante é o baseado na Lei de Raoult, válido para misturas e soluções ideais. Inicialmente, revisam-se os conceitos de refrigerantes mistos, curvas compostas e o ponto de pinça, utilizados na implementação da solução computacional. A aplicação dos modelos de gás e solução ideal influencia nos resultados, mas, não obstante, produz bons resultados como os obtidos no presente trabalho. A operação eficiente do ciclo depende, sobretudo, de três parâmetros principais, quais sejam: vazão da mistura refrigerante, razão de pressões alta e baixa do ciclo de refrigeração e composição da mistura refrigerante. Da análise dos resultados obtidos conclui-se que a alteração nas proporções da composição do refrigerante muda significativamente a forma das curvas composta quente e composta fria, quando comparados à alteração dos níveis de pressão e da vazão do ciclo refrigerante. Entretanto, a operacionalização do ciclo somente ocorre se um dado conjunto de valores daqueles parâmetros satisfaça uma determinada diferença mínima de temperatura, ou ponto de pinça, entre as curvas composta quente e composta fria dentro do trocador de calor. Assim, a operação eficiente do ciclo de refrigeração requer a otimização daqueles três parâmetros operacionais.

Palavras- chave: Liquefação, planta de pequena escala, refrigerante misto, gás natural liquefeito, Análise de pinça. 


\section{INTRODUÇÃO}

Diante da necessidade mundial de energia e, mais especificamente, energia mais limpa, o gás natural (GN) por suas características e disponibilidade tornou-se uma fonte de energia importante para diferentes tipos de aplicações industriais e também residenciais. Dentre as diversas etapas que compõem a cadeia de processamento do gás natural, a liquefação é de grande importância porque promove o aumento da densidade energética do gás natural, viabilizando assim, o seu transporte e armazenamento de forma competitiva com outros energéticos e processos. $\mathrm{O}$ produto da etapa de liquefação é o gás natural liquefeito (GNL) que possui densidade energética maior do que o gás natural comprimido (GNC) na fase gasosa, cerca de 3,1 vezes. A liquefação reduz o volume do $\mathrm{GN}$ em aproximadamente 610 vezes.

O processo de liquefação do gás natural é, basicamente, um ciclo de refrigeração. A produção de GNL a temperaturas criogênicas $\left(-161{ }^{\circ} \mathrm{C}\right)$ é realizada em plantas de liquefação classificadas segundo a capacidade de produção, as quais podem ser de pequena ou grande escala. Devido ao crescimento de consumo de gás natural como combustível limpo e rentável e por mercados que não dispõem de uma rede de gasoduto, consideráveis avanços foram realizados nos projetos de plantas de gás natural liquefeito (GNL) de pequena escala. Na atualidade, existem diversas plantas de GNL em operação e são vários os projetos e tecnologias em desenvolvimento dessas plantas. As plantas de produção de pequena escala em comparação com plantas de GNL de grande escala, caracterizam-se por ter uma configuração mais simples, menor quantidade de equipamentos, flexibilidade de operação do processo e por serem economicamente viáveis.

As tecnologias de produção em plantas de pequena escala provadas são os ciclos de refrigeração de expansão e os ciclos de refrigeração mista que usam mistura de hidrocarbonetos mais o nitrogênio como refrigerante. Podemos citar alguns processos de liquefação comerciais de pequena escala usando ciclos de refrigeração de expansão: Kryopak EXP e Hamworthy, enquanto que os processos que utilizam ciclos de refrigeração mista, menciona-se o de Black e Veatch (PRICO) e Kryopak RMPR.

Como a eficiência termodinâmica e o projeto compacto são importantes nos critérios de seleção das tecnologias de produção, a otimização de uma planta de GNL passa, obrigatoriamente, pela busca de otimização daqueles critérios.

Diversos trabalhos foram realizados em processos de liquefação de ciclos de refrigeração mista. Por exemplo, Mah e Lin (1978) implementaram um modelo computacional para simular o ciclo de liquefação usando refrigerante misto; Lee e outros (2002), desenvolveram um modelo não linear aplicando a análise termodinâmica para selecionar a composição ótima do refrigerante misto; Remeljej (2005) realizou um estudo comparativo da eficiência de quatro processos de liquefação de pequena escala, entre eles o ciclo PRICO; e Jensen e Skogestad (2006) identificaram variáveis de controle para a operação ótima do ciclo PRICO. Para a otimização e análise destes ciclos se utiliza a análise termodinâmica e programação matemática.

O objetivo deste trabalho é analisar um ciclo de refrigeração mista, centrando a análise no Trocador de Calor Criogênico Principal (TCCP), equipamento central de qualquer ciclo de liquefação. A metodologia está baseada na aplicação da Lei de Raoult como modelo termodinâmico ideal e nos conceitos da análise de pinça que visa a otimização do processo e melhora o uso eficiente da energia. Dois conceitos da análise de pinça são considerados para a análise deste processo, as curvas compostas e o ponto de pinça (pinch point). As curvas compostas quente e fria são construídas a partir de dados de correntes derivadas de um balanço de massa e energia do processo. A transferência de calor é realizada na zona delimitada por duas curvas compostas (uma quente e uma fria), portanto, deve ser estabelecida uma diferença mínima de temperatura entre elas, a qual se observa normalmente em um único ponto, denominado ponto de pinça.

Segundo Lee e outros (2002), a otimização do processo se realiza controlando e ajustando variáveis como os níveis de pressão (alta/baixa) do sistema de refrigeração, a taxa do fluxo do refrigerante misto e a composição do refrigerante. Para realizar este estudo, se trabalhará com o ciclo Prico (Poly Refrigerant Integrates Cycle Operations) por ser um processo simples e bem difundido em comparação aos outros processos de liquefação. 


\section{PLANTAS DE LIQUEFAÇÃO DE GNL}

A indústria do GNL tem mais de 40 anos de história. A primeira planta de liquefação foi construída no continente africano, na Argélia e entrou em operação em 1964. Através dos anos diferentes processos de liquefação foram desenvolvidos e as plantas de liquefação começaram a produzir vários milhões de toneladas por ano $\left(10^{6} \mathrm{t} / \mathrm{ano}\right)$ de GNL. As primeiras plantas consistiram de processos de liquefação baseados em ciclos cascata e refrigerante misto simples, as capacidades eram menos do que $1 \times 10^{6} \mathrm{t} /$ ano num trem de produção (Unidades paralelas que tratam, liquefazem e logo enviam o GNL aos tanques de armazenamento). Atualmente nas plantas de grande escala existem novos ciclos de liquefação que

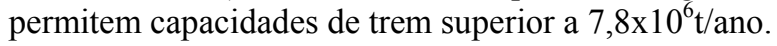

As plantas de pequena escala tipicamente têm capacidades de $10-5000$ toneladas por dia (t/d). As mini plantas de GNL usadas, por exemplo, em estações de combustíveis e as plantas de peakshaving (fornece GN durante períodos de alta demanda) encontram-se dentro da classificação de plantas de pequena escala. As plantas de peakshaving podem chegar a ter capacidades maiores a $1000 \mathrm{t} / \mathrm{d}$. Segundo a capacidade de produção, de acordo a literatura, classificaram-se as plantas de liquefação em quatro categorias mostradas na Tabela 1.

Tabela 1 - Capacidades de produção de plantas de GNL (adaptado de Chart Energy (2007), Price (2003), Finn e outros (1999), Hamworthy (2006)).

\begin{tabular}{llcc}
\hline \multicolumn{2}{c}{ Descrição da planta de GNL } & t/d & $\mathbf{1 0}^{\mathbf{6}}$ t/ano \\
\hline \multirow{2}{*}{$\begin{array}{l}\text { Pequena } \\
\text { escala }\end{array}$} & Mini plantas & $10-200$ & $0,0034-0,07$ \\
\multirow{2}{*}{ Grande escala } & Peakshaving & $100-500$ & $0,034-0,17$ \\
& Base Load & $1000-4000$ & $0,34-1,36$ \\
\hline
\end{tabular}

Uma planta Base Load, normalmente é operada para tomar a totalidade ou parte da carga mínima de um sistema, e conseqüentemente, que produz energia essencialmente a uma taxa constante e opere continuamente. (Energy Information Administration, 2008).

As plantas de liquefação típicas estão formadas por diferentes processos: pré-tratamento de GN, liquefação, armazenamento e carregamento de GNL. A configuração ou estrutura de uma planta de liquefação depende da composição do GN, especificações do produto final e das condições locais (Shukri, 2004). Na Figura 1 mostra-se o fluxograma de uma planta de liquefação típica.

A operação da planta inicia-se com a recepção do GN, o qual é proveniente ou do gasoduto ou de uma UPGN. Este chega da rede de gasodutos a uma elevada pressão, a qual tem que ser ajustada à pressão de operação da planta. Nesta etapa, também são realizadas medições das propriedades do fluido.

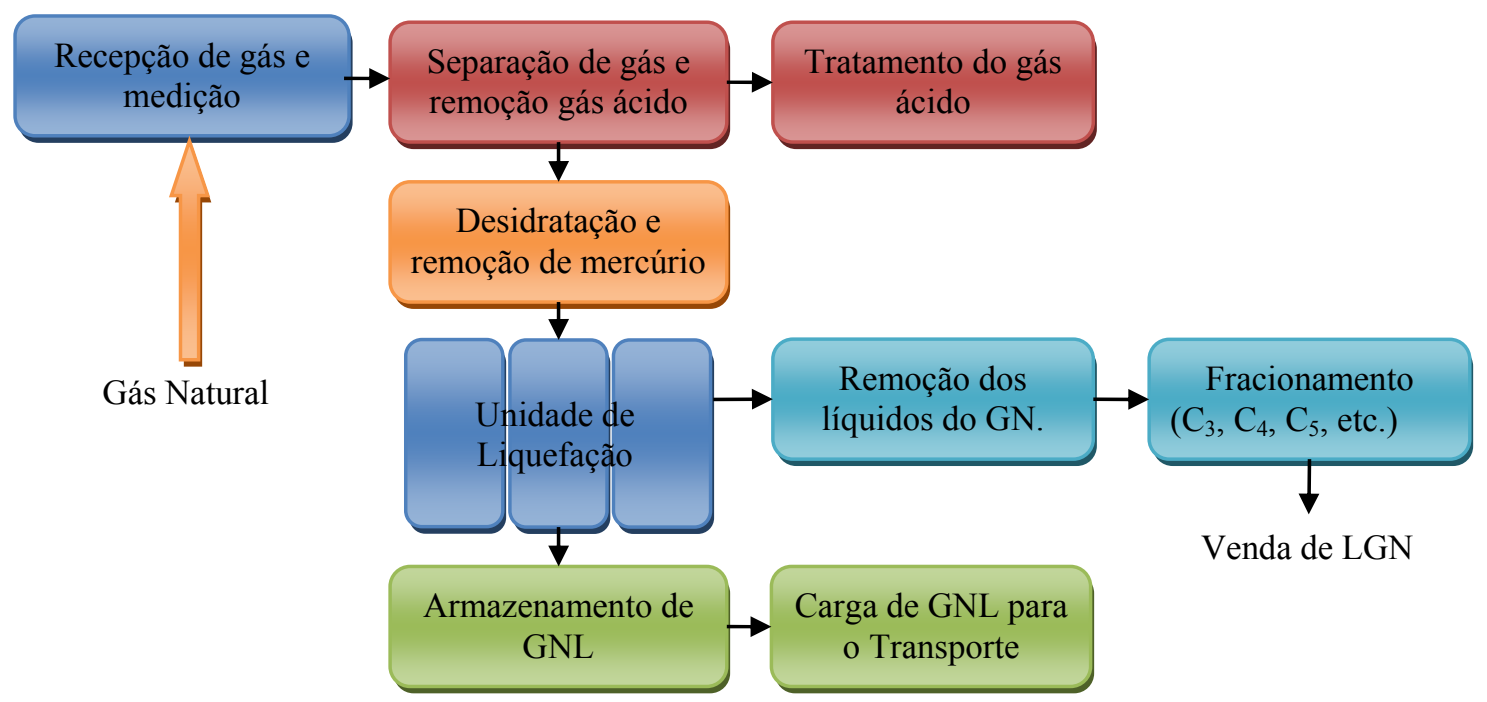

Figura 1 - Componentes de uma planta de GNL. 


\subsection{UNIDADE DE LIQUEFAÇÃO}

Este é o processo-chave das plantas de liquefação, o qual é baseado no princípio de operação do ciclo de refrigeração. Os componentes principais que formam a unidade de liquefação são: os compressores, dispositivos de expansão, trocadores de calor, bombas e separadores. A capacidade da unidade de liquefação é determinada pelo tamanho destes componentes, os refrigerantes empregados e o tipo de processo de liquefação. Segundo Mokhatab e Wood (2007), Finn e outros (1999), três tipos genéricos de ciclos de refrigeração são utilizados: o ciclo cascata, refrigerante misto e de expansão. Cada um deles pode passar por algumas modificações no processo de liquefação de acordo aos requerimentos da planta.

Nos processos de liquefação normalmente se empregam vários trocadores de calor, mas o processo principal de liquefação ocorre no trocador de calor criogênico principal (TCCP), em inglês, Main Criogenic Heat Exchanger (MCHE). Os trocadores de calor de placas de alumínio e trocadores de calor de tubo espiral normalmente são aplicados para este processo criogênico.

A Figura 2 ilustra um ciclo de liquefação de Refrigerante Misto (RM). O principio de funcionamento se dá pelo resfriamento do GN usando uma mistura de diferentes fluidos refrigerantes, geralmente formada por o gás nitrogênio mais hidrocarbonetos leves, tais como o metano, etano, propano e butano em proporções variadas. A mistura de refrigerantes é comprimida no compressor (C) e logo resfriada em um trocador de calor (TC), a mistura refrigerante à pressão elevada é parcialmente condensada naquele trocador de calor. Logo a mistura refrigerante atravessa o trocador de calor principal (TCCP) vindo a formar a "corrente quente", como ilustrada. Depois o fluxo da mistura refrigerante quente alcança um dispositivo de expansão. O dispositivo de expansão pode ser uma válvula de efeito Joule-Thompson (VE), onde a mistura refrigerante sofre um estrangulamento adiabático, diminuindo a sua temperatura do refrigerante. Alternativamente, se o dispositivo for um turbo-expansor (TEX), a energia útil extraída da expansão da mistura refrigerante como potência de eixo do turbo-expansor $\left(\dot{\mathrm{W}}_{\mathrm{E}}\right)$, pode ser upsada para acionar um compressor ou gerar eletricidade. No processo de expansão quase-isoentropico no TEX, a temperatura da mistura de refrigerante diminui consideravelmente em comparação ao processo de expansão por estrangulamento adiabático. Depois da expansão, a mistura de refrigerante, agora à temperatura criogênica e denominada "corrente fria", retorna ao TCCP resfriando continuamente o gás natural, bem como a sua própria corrente quente. $\mathrm{O}$ refrigerante com baixa pressão, agora quente e vaporizado sai do TCCP em direção ao compressor para completar o ciclo. Do lado do gás natural, este ingressa no TCCP com as condições de entrega geralmente a temperatura ambiente e pressão moderada para alta (alimentação do gás), e sai do TCCP parcialmente condensado a elevada pressão para sofrer um processo posterior de expansão, como indicado na figura.

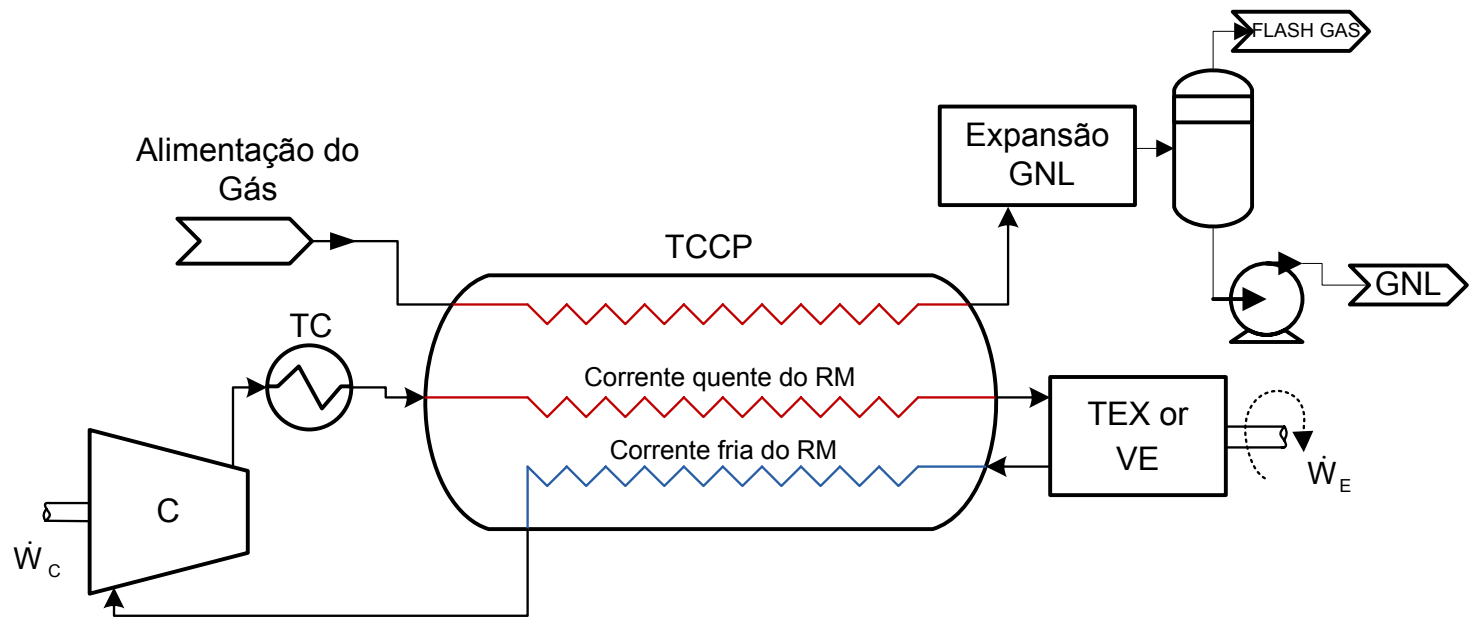

Figura 2 - Esquema geral de um ciclo de refrigeração (Tacuse e Simões-Moreira, 2007).

Finalmente, o fluxo do gás natural passa através de um tanque de "flash" onde a fase vapor é separada da fração liquida ( $\sim 90 \%$ de líquido), se na composição do gás natural houver gases não condensáveis (nitrogênio), estes ficarão retidos na fase vapor dentro do tanque de "flash". Essa mistura de gases pobres pode ser utilizada como gás combustível em outra parte da planta de liquidificação. $\mathrm{O}$ vapor tem maior 
proporção de nitrogênio (gás não-condensável) que pode ser usado como gás combustível. O gás natural liquefeito é bombeado até os tanques de armazenamento.

\subsection{CICLOS DE LIQUEFAÇÃO DE PEQUENA ESCALA}

De um ponto de vista geral, os processos de liquefação para pequena escala podem ser agrupados em dois grandes grupos: os processos de ciclo aberto (em inglês, open-loop), nos quais, o gás de alimentação, forma parte do fluido refrigerante e os processos de ciclo fechado (em inglês, closed-loop) em que, a liquefação do GN é obtida por um fluido refrigerante auxiliar (mistura de hidrocarbonetos mais nitrogênio) que recircula continuamente num circuito separado.

Os sistemas de ciclo aberto são baseados principalmente num processo sucessivo de compressão, resfriamento e expansão do GN. Usualmente a última etapa de expansão é realizada num turbo-expansor (TEX) para a obtenção de GNL.

Sistemas de ciclo fechado usam como fluido refrigerante o nitrogênio ou uma mistura de hidrocarbonetos para resfriar o GN. Mistura de nitrogênio, metano e outros hidrocarbonetos $\left(\mathrm{C}_{2}, \mathrm{C}_{3}, \mathrm{C}_{4}\right.$, etc.), são aplicados nos ciclos de refrigerante misto (RM). A Tabela 2 resume alguns ciclos comerciais de acordo com a classificação apresentada acima e proporciona informação relevante com relação às tecnologias, eficiências e capacidades (Tacuse e Simões-Moreira, 2007).

Tabela 2 - Plantas de pequena escala, eficiência e capacidade (Tacuse e Simões-Moreira, 2007).

\begin{tabular}{|c|c|c|c|c|c|}
\hline Classificação & $\begin{array}{c}\text { Ciclo de } \\
\text { Refrigeração }\end{array}$ & $\begin{array}{l}\text { Processo de } \\
\text { Liquefação }\end{array}$ & $\begin{array}{c}\text { Eficiência } \\
\text { Global } \\
\text { kW-dia/ton }\end{array}$ & Capacidade & Referência \\
\hline \multirow{5}{*}{$\begin{array}{l}\text { Ciclo fechado } \\
\text { (Closed-loop) }\end{array}$} & \multirow{3}{*}{$\begin{array}{l}\text { Refrigerante } \\
\text { Misto } \\
\text { (RM) }\end{array}$} & $\begin{array}{c}\text { Black and Veatch } \\
\text { PRICO }\end{array}$ & 16,8 & $1,310^{6} \mathrm{t} / \mathrm{ano}$ & Salof, 2006 \\
\hline & & GTI & $*$ & $1880 \mathrm{~kg} / \mathrm{d}$ & GTI, 2003 \\
\hline & & Kryopak RMPR & 13,0 & $210 \mathrm{t} / \mathrm{d}$ & Salof, 2006 \\
\hline & $\operatorname{TEX}\left(\mathrm{N}_{2}\right)$ & Hamworthy & * & 30 a $500 \mathrm{t} / \mathrm{d}$ & $\begin{array}{l}\text { Hamworthy, } \\
2006\end{array}$ \\
\hline & $\operatorname{TEX}\left(\mathrm{N}_{2} \& \mathrm{C}_{1}\right)$ & $\begin{array}{l}\text { Pré-resfriado } \\
\text { Dual TEX }\end{array}$ & 13,0 & $0,510^{6} \mathrm{t} / \mathrm{ano}$ & $\begin{array}{l}\text { Foglietta, } \\
2004\end{array}$ \\
\hline \multirow{5}{*}{$\begin{array}{l}\text { Ciclo aberto } \\
\text { (Open-loop) }\end{array}$} & \multirow{4}{*}{ TEX } & Dual TEX ${ }^{+}$ & 16,5 & $0,510^{6} \mathrm{t} / \mathrm{ano}$ & $\begin{array}{l}\text { Foglietta, } \\
2004\end{array}$ \\
\hline & & Kryopak EXP & 15,5 & $147 \mathrm{t} / \mathrm{d}$ & Salof, 2006 \\
\hline & & Idaho (Letdown) & $*$ & $17790 \mathrm{~kg} / \mathrm{d}$ & $\begin{array}{l}\text { Cascone, } \\
2005\end{array}$ \\
\hline & & Stirling & $*$ & $\begin{array}{l}1200 \mathrm{~kg} / \mathrm{d}- \\
10000 \mathrm{~kg} / \mathrm{d}\end{array}$ & $\begin{array}{l}\text { Kirillov, } \\
2004\end{array}$ \\
\hline & $\begin{array}{l}\text { Tubo de } \\
\text { Vórtices }\end{array}$ & - & $*$ & $12000 \mathrm{~kg} / \mathrm{d}$ & $\begin{array}{l}\text { Kirillov, } \\
2004\end{array}$ \\
\hline
\end{tabular}

\section{SISTEMA DE REFRIGERANTE MISTO (RM)}

O princípio básico para resfriar e liquefazer o gás natural usando uma mistura de refrigerantes, implica na semelhança das curvas de resfriamento/aquecimento do gás natural e da mistura de refrigerantes deslocadas de uma diferença de temperatura. Estas duas curvas deverão ser as mais próximas possíveis, mantida uma diferença mínima de temperatura $\left(\Delta T_{\text {min }}\right)$ entre elas, para que se obtenha a maior eficiência do processo termodinâmico e, com isso, um menor consumo de potência de acionamento dos compressores por unidade de massa de GNL produzido (Shukri, 2004). As curvas típicas do gás natural e refrigerante podem-se visualizadas com o auxílio do diagrama temperatura-entalpia como se mostra na Figura 3. Nesta figura, uma curva típica de resfriamento do gás natural é indicada (linha espessa). 


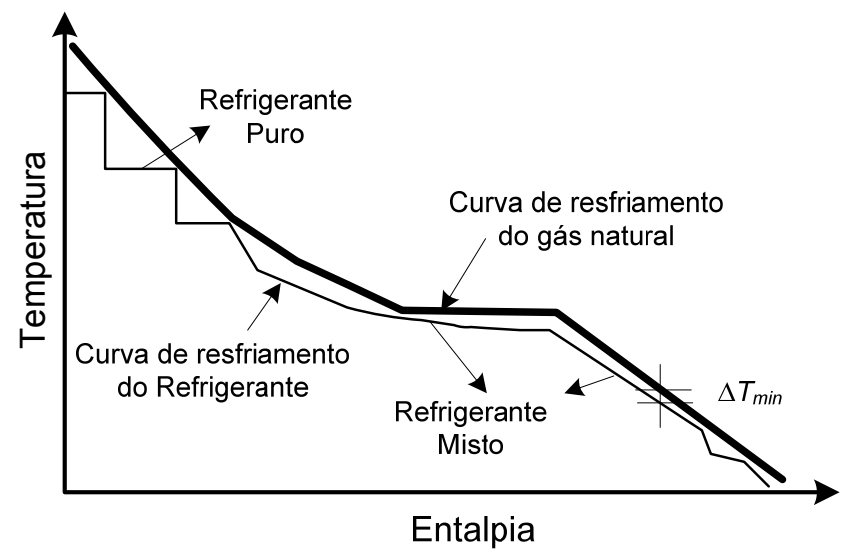

Figura 3 - Curvas de resfriamento típicas do gás natural/refrigerante (adaptado de Shukri, 2004).

Observando a curva de resfriamento do refrigerante da Figura 3, nota-se que com refrigerantes puros não se consegue uma curva semelhante à curva de resfriamento do gás natural, devido à ocorrência de patamares isotérmicos de mudança de fase. Mas, usando refrigerantes mistos ou multicomponentes, podese conseguir o objetivo, devido ao fato de que a mistura não possui patamares de temperaturas constantes e a curva de resfriamento do gás natural pode, em principio, ser obtida num trocador de calor em contracorrente.

O sistema de refrigeração no processo de liquefação determina, em grande medida, o consumo específico de energia e os custos de capital. Para minimizar o consumo de energia e os investimentos de capital, a técnica que será empregada está baseada nos conceitos da análise de pinça ou, em inglês, pinch analysis. A próxima seção (Seção 4) detalha dois conceitos da análise de pinça, os quais são baseados nos trabalhos de Linnhoff (1998) e Canmet Energy Technology Center (2003).

\section{CURVAS COMPOSTAS E PONTO PINÇA (PINCH POINT)}

Em primeiro lugar é preciso definir o que são as curvas compostas quente e fria. Para isso, explicaremos como se formam as curvas compostas para um ciclo de liquefação PRICO de estágio simples, representado de forma simplificada na Figura 4. O centro da análise será realizado no trocador de calor criogênico principal (TCCP), onde as correntes do processo darão lugar às curvas compostas.

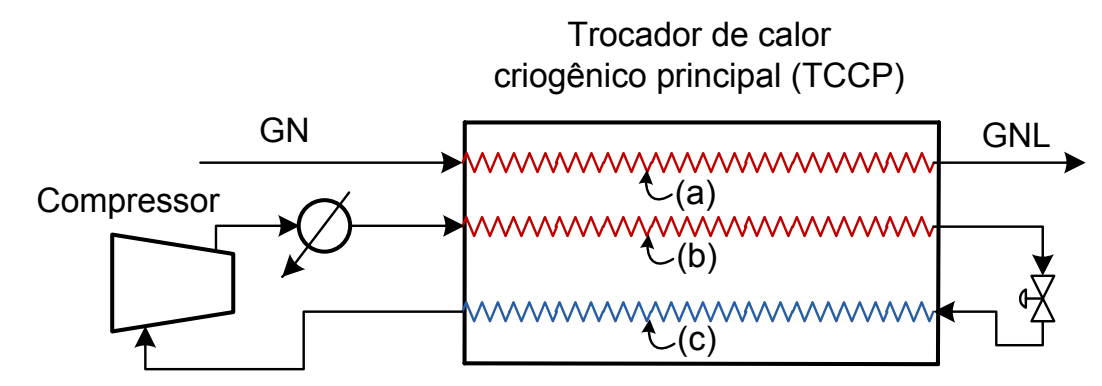

Figura 4 - Diagrama simplificado do processo Prico. (a) corrente GN-GNL; (b) corrente refrigerante aquecido; (c) corrente refrigerante fria.

Com relação à Figura 4, no trocador de calor se observam três correntes e as nomearemos de: (a) corrente GN - GNL, (b) corrente do refrigerante aquecido (situada antes da válvula), e (c) corrente do refrigerante fria (situada depois da válvula). Agora, determinam-se quais são as correntes quentes e frias no processo. A corrente GN - GNL e a corrente do refrigerante aquecido são correntes quentes, porque elas precisam ser resfriadas. Portanto, elas são combinadas formando uma curva composta quente. Enquanto que a corrente do refrigerante fria constituirá a curva composta fria. Os perfis destas curvas estão representados na Figura 5 em um diagrama de temperatura-entalpia. 


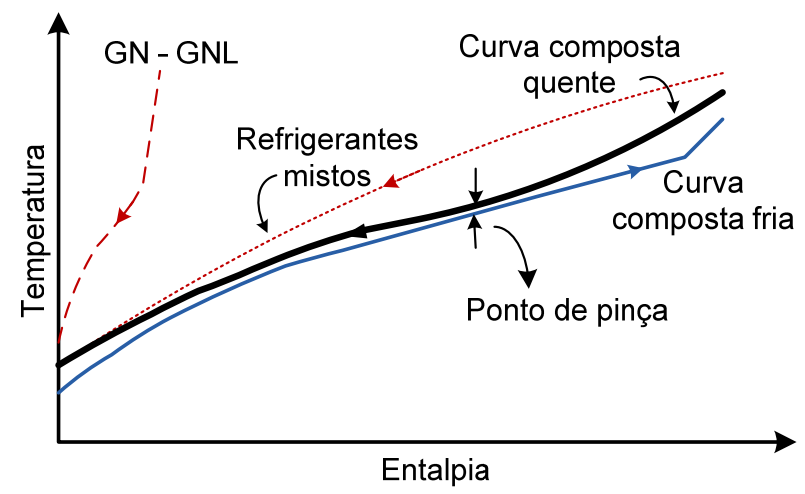

Figura 5 - Curvas compostas para o processo PRICO (Lee e outros, 2002).

As curvas compostas são construídas a partir de dados de correntes derivadas de um balanço de massa e energia do processo. Em uma curva composta, os incrementos de entalpia são a soma dos incrementos de cada corrente. Na construção da curva composta quente, as entalpias da corrente GN - GNL (tracejado na figura) e da corrente do refrigerante aquecido (curva pontilhada na figura) são somadas e conseqüentemente dará lugar a uma curva composta quente (Linha espessa continua) com entalpias totais a uma dada temperatura, mudando o perfil (inclinação da curva). Na Figura 5, também esta indicada a curva composta fria (linha fina continua).

Na Figura 5 observa-se que a transferência de calor é realizada na zona delimitada pelas duas curvas compostas (fria e quente). Evidentemente, para que ocorra transferência de calor, a temperatura da curva quente deverá sempre ser maior que a temperatura da curva composta fria numa dada seção do trocador de calor em que ambos estão em contato. Isto nos leva a dizer, que as curvas compostas não podem cruzar-se ou igualar-se (temperatura de cruzamento) porque, do contrário, não haverá troca de calor. Portanto, deve ser estabelecida uma diferença mínima de temperaturas $\left(\Delta T_{\min }\right)$ entre as duas curvas compostas. A diferença mínima de temperaturas entre as curvas compostas quente e fria se observa normalmente em um único ponto, denominado ponto pinça.

Para evitar o cruzamento de temperaturas dentro do trocador de calor no processo de refrigerantes mistos, é requerida uma elevada taxa do fluxo do refrigerante. Na Figura 6 se mostra o cruzamento indesejável de temperatura.

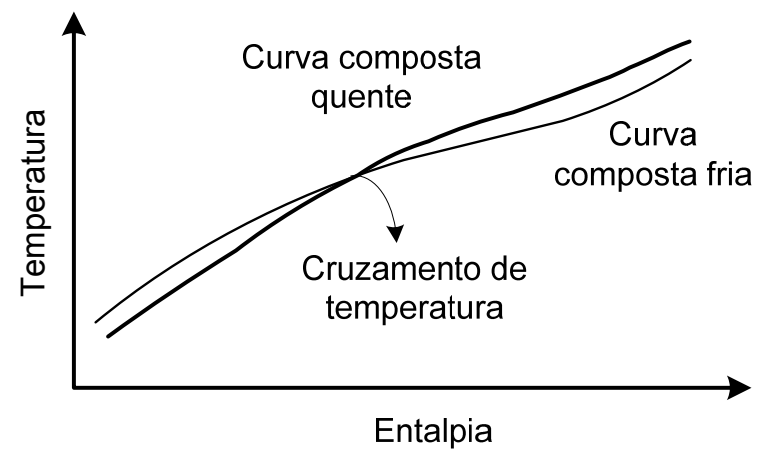

Figura 6 - Cruzamento de temperatura entre as curvas compostas.

Segundo Linnhoff (1998), os valores típicos de $\Delta T_{\min }$ para processos criogênicos, vão desde 3 até $5^{\circ} \mathrm{C}$. No trabalho de Remeljej e Hoadley (2006), empregam uma diferença mínima de temperatura de $2{ }^{\circ} \mathrm{C}$ na simulação de quatro diferentes processos de liquefação de pequena escala.

\section{METODOLOGIA}

No capítulo anterior, revisaram-se conceitos de refrigerantes mistos, curvas compostas e o ponto de pinça. Estes conceitos são utilizados na implementação do modelo computacional junto às equações de equilíbrio vapor/líquido e das propriedades termodinâmicas. O modelo termodinâmico utilizado é a Lei de Raoult que aplica o modelo de gás ideal e modelo de solução ideal para o equilíbrio vapor/líquido. 
A implementação do modelo computacional foi realizada na plataforma EES (Engineering Equation Solver), a lógica do programa esta desenvolvida em uma serie de procedimentos e subprogramas junto a equações de balanço de massa e energia que permitem calcular a entalpia e entropia da mistura. Com estes resultados, logo, é possível construir as curvas de resfriamentos do gás natural, curvas das correntes quente e fria do sistema de refrigeração em um diagrama temperatura-fluxo de entalpia.

Condições de simulação são adotadas como padrão como base de comparação das diversas simulações do ciclo PRICO.

\subsection{MODELO TERMODINÂMICO - LEI DE RAOULT}

As propriedades termodinâmicas dos sistemas multicomponentes ou refrigerantes mistos dependem da composição como também da temperatura e da pressão. O critério para o equilíbrio líquido/vapor multicomponente é proporcionado pelo potencial químico, eq. (1):

$$
\mu_{i}^{v}=\mu_{i}^{l} \quad(i=1,2, \ldots, N)
$$

Onde N é o número de espécies presentes no sistema. Os potenciais químicos são funções da temperatura, pressão e da composição. Aplicando-se o modelo de gás ideal à fase vapor e o modelo de solução ideal à fase liquida, se obtém uma expressão simples e útil para o equilíbrio vapor/líquido, conhecida como a Lei de Raoult, eq. (2), (Smith e outros, 1996).

$$
\mathrm{y}_{\mathrm{i}} \mathrm{P}=\mathrm{x}_{\mathrm{i}} \mathrm{P}_{\mathrm{i}}^{\mathrm{sat}} \quad(\mathrm{i}=1,2, \ldots, \mathrm{N})
$$

Onde, $\mathrm{y}_{\mathrm{i}}$ é a fração molar da fase vapor do componente i, $\mathrm{P}$ a pressão do sistema, $\mathrm{x}_{\mathrm{i}}$ é a fração molar da fase líquida e $P_{i}^{\text {sat }}$ é a pressão de saturação daquele componente $i$.

O conceito dos modelos de gases ideais e da solução ideal é um conceito limite bastante simplificado que falha em fornecer uma representação realista do comportamento real, mas permite estabelecer um marco de comparação.

O cálculo das propriedades termodinâmicas, entalpia e entropia, da mistura têm o seguinte procedimento:

- Cálculo da Temperatura de orvalho do sistema, ver Figura 7,

- Cálculo do equilíbrio usando a eq. (7),

- Cálculo da entalpia da mistura usando a eq. (8).

De acordo com o diagrama da Figura 7, para efetuar o cálculo da temperatura de orvalho é necessária uma temperatura estimada ( $\mathrm{T}_{\text {estimada }}$ ), a pressão do sistema e a composição da fase vapor. O programa, então, calcula a temperatura de orvalho final através de um processo iterativo. A nomenclatura do fluxograma mostrado na Figura 7 denota o seguinte: $\Delta \mathrm{T}$ é o diferencial de temperatura, $\mathrm{T}_{1}$ e $\mathrm{T}_{2}$ são as temperaturas de aproximação, IC é um indicativo de condensação, igual a 1 se houver condensação, E é a tolerância e TORV é a temperatura de orvalho que se deseja calcular.

Para o balanço de massa e da composição de uma corrente de duas fases considera-se que o sistema contém 1 mol de espécies químicas $(\mathrm{L}+\mathrm{V}=1)$, onde $\mathrm{L}$ representa os moles da fase liquida e $\mathrm{V}$ os moles da fase vapor, portanto as composições são relacionadas pelas seguintes equações:

$$
\begin{gathered}
\mathrm{Z}_{\mathrm{i}}=\mathrm{x}_{\mathrm{i}} \mathrm{L}+\mathrm{y}_{\mathrm{i}} \mathrm{V} \\
\mathrm{K}_{\mathrm{i}}=\mathrm{y}_{\mathrm{i}} / \mathrm{x}_{\mathrm{i}}=\mathrm{P}_{\mathrm{i}}^{\text {sat }} / \mathrm{P}
\end{gathered}
$$

Onde $Z_{i}$ é a composição global do sistema. Atendendo à lei da conservação de massa, as frações molares de todos os componentes da mistura devem somar 1 tanto na fase vapor como a fase líquida, assim:

$$
\begin{array}{ll}
\sum_{i} y_{i}=1 & (i=1, \ldots, N) \\
\sum_{i} x_{i}=1 & (i=1, \ldots, N)
\end{array}
$$




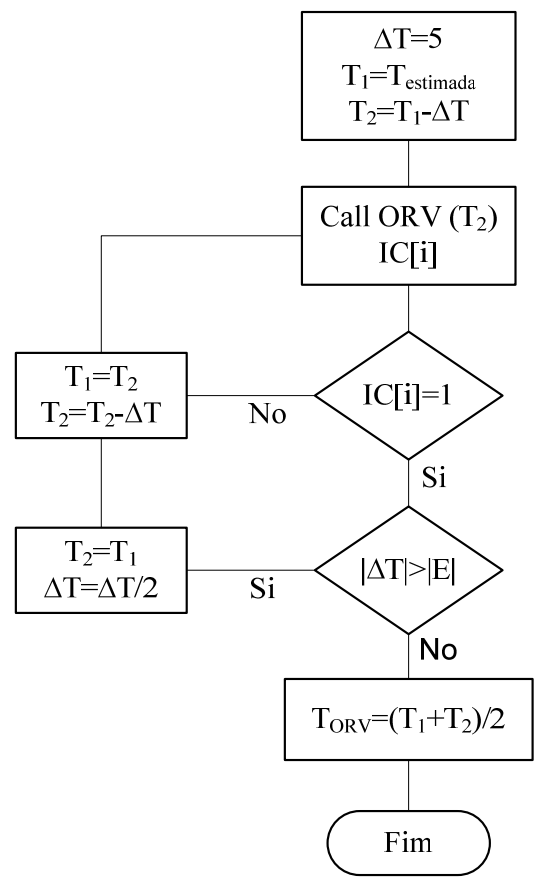

Figura 7 - Fluxograma para o cálculo da temperatura de orvalho.

A mudança de fase ocorre em uma faixa de temperatura determinada, desde a temperatura de orvalho até a temperatura de bolha. Se a temperatura indica que a corrente está na fase vapor, então: $V=1, \mathrm{y}_{\mathrm{i}}=\mathrm{Z}_{\mathrm{i}} \mathrm{e}$ $\mathrm{x}_{\mathrm{i}}=0$ mas, se indica que está na fase líquida, então: $\mathrm{V}=0, \mathrm{x}_{\mathrm{i}}=\mathrm{Z}_{\mathrm{i}}$ e $\mathrm{y}_{\mathrm{i}}=0$.

Segundo Smith e outros (1996), o cálculo do equilíbrio empregando a Lei de Raoult é realizado pela equação:

$$
\sum \frac{\mathrm{Z}_{\mathrm{i}} \mathrm{K}_{\mathrm{i}}}{1+\mathrm{V}\left(\mathrm{K}_{\mathrm{i}}-1\right)}=1
$$

O programa efetua o cálculo do equilíbrio para cada componente utilizando a temperatura de orvalho (condensação) da mistura. Este cálculo determina a fração molar do líquido, fração molar do vapor e o título na mudança de fase.

No fluxograma da Figura 8, observa-se como e realizado o cálculo do equilíbrio. A nomenclatura do fluxograma denota o seguinte: TM é a temperatura da mistura, TC a temperatura critica, ICC é o indicativo de condensação na mudança de fase, I é o contador que conta a quantidade de vezes que se realiza o ciclo, $\mathrm{N}$ o número de componentes, TL a temperatura limite do Programa, PM a pressão da mistura, $\mathrm{P}_{\text {parc }}$ a pressão parcial do componente $\mathrm{i}$ e $\mathrm{P}_{\text {sat }}$ a pressão de saturação de componente $\mathrm{i}$ respectivamente.

Neste sistema de duas fases (liquido/vapor) em equilíbrio, o valor total da entalpia da mistura (função da temperatura, pressão e da composição da mistura), é a soma da entalpia total das fases, é obtida conforme à expressão seguinte:

$$
h=(1-x) h^{\prime}+x h^{v}
$$

Para o propósito da análise do ciclo de refrigerante misto, assume-se que a transferência de calor com a vizinhança do trocador de calor em contracorrente é desprezível, a entalpia de cada fluxo depende só da temperatura dada uma composição, as trocas de energia cinética e potencial são desprezíveis. 


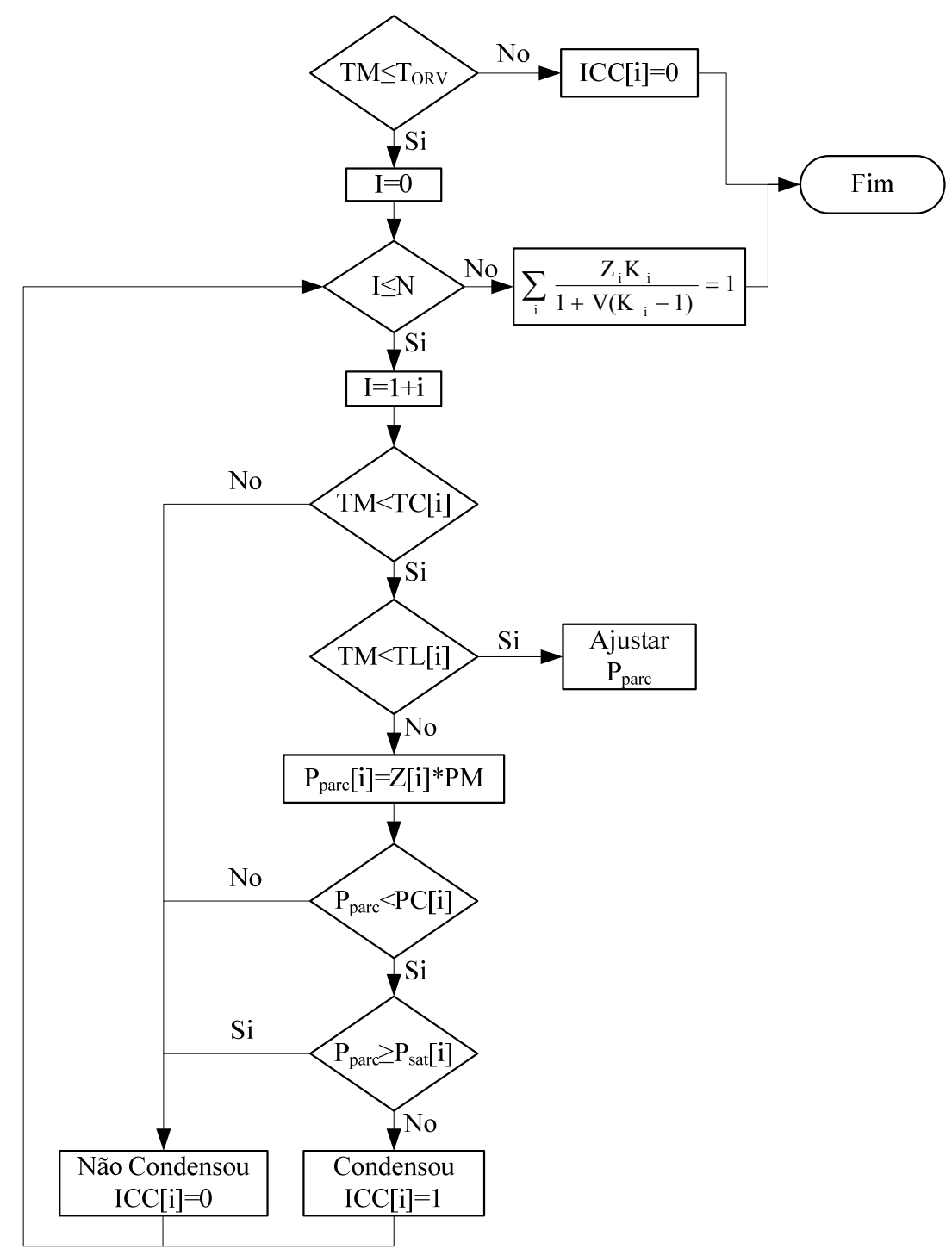

Figura 8 - Fluxograma para o cálculo do equilíbrio.

Os dados básicos das correntes de processo para a aplicação da análise de pinça são: temperatura, vazão mássica, calor específico. Portanto, a taxa de transferência de calor é dada pela eq. 9 , valida para a corrente quente e corrente fria:

$$
\dot{\mathrm{Q}}=\dot{\mathrm{m}}\left(\mathrm{h}_{\mathrm{s}}-\mathrm{h}_{\mathrm{e}}\right) \equiv(\Delta \dot{\mathrm{H}})
$$

Onde, $\dot{m}, h_{s}$ e $h_{e}$ denotam vazão, entalpia de saída e entalpia de entrada respectivamente.

No trocador de calor do processo PRICO existem três correntes, duas quentes e uma corrente fria. A técnica da análise de pinça consiste em associar as características de temperaturas das duas correntes quentes para a construção de uma curva composta quente.

Para o caso de mudança de fase, a entalpia de vaporização é usada para o cálculo da taxa de variação de entalpia das correntes do processo, eq. 10:

$$
\Delta \dot{\mathrm{H}}=\dot{\mathrm{m}}\left(\Delta \mathrm{h}_{\text {vap }}\right)
$$

No caso onde não existe mudança de fase, a taxa da variação de entalpia para um determinado intervalo de temperatura é dada pela eq. 11 . 


$$
\Delta \dot{\mathrm{H}}=\dot{\mathrm{m}} \mathrm{c}_{\mathrm{p}} \Delta \mathrm{T}
$$

Cada perfil das correntes quentes apresenta uma taxa de capacidade calorífica diferente $\left(\dot{\mathrm{m}} \mathrm{c}_{\mathrm{p}}\right)$ num determinado intervalo de temperatura, por isto, a taxa da variação de entalpia para a construção da curva composta quente é dada pela eq. 12:

$$
\Delta \dot{\mathrm{H}}_{\mathrm{cq}}=\left(\dot{\mathrm{m}}_{1} \mathrm{c}_{\mathrm{p} 1}+\dot{\mathrm{m}}_{2} \mathrm{c}_{\mathrm{p} 2}\right) \Delta \mathrm{T}
$$

Finalmente, obtêm-se as curvas compostas no diagrama temperatura - variação de entalpia considerando que, para o menor valor de temperatura da curva composta quente ou fria, a entalpia é zero. Assim, consegue-se achar a taxa da variação de entalpia total de cada curva composta.

\subsection{PARÂMETROS DE SIMULAÇÃO DO CICLO PRICO}

No diagrama do ciclo PRICO da Figura 9, mostra-se a identificação dos pontos de avaliação das propriedades termodinâmicas. As correntes que atravessam o trocador de calor são três, duas correntes quentes (GN-GNL e 3-4) em contracorrente com uma corrente fria (5-1).

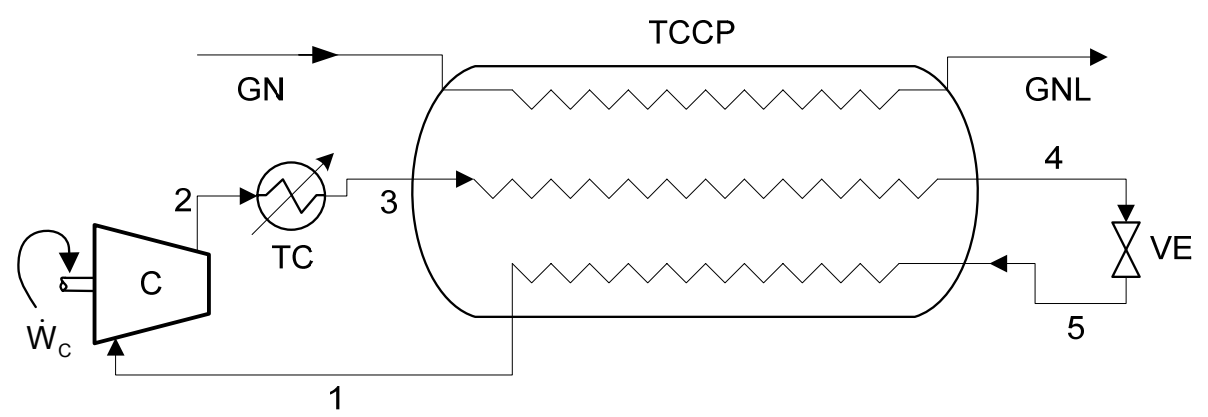

Figura 9 - Diagrama de identificação dos pontos de avaliação no ciclo PRICO.

O gás natural que entra no TCCP é um gás processado, livre de água e gases ácidos. A Tabela 3 mostra a composição do gás natural dotada para a simulação, esta composição, normalizada excluindo o propano e dióxido de carbono, corresponde ao gás processado ou residual da unidade de processamento de gás natural localizada no município de Candeias na Bahia (Conpet, 2008).

Tabela 3 - Composição do GN.

\begin{tabular}{lc}
\hline \multicolumn{1}{c}{ Elemento } & Fração Molar \\
\hline Metano & 0,8952 \\
Etano & 0,0927 \\
Nitrogênio & 0,0121 \\
\hline
\end{tabular}

A concentração do nitrogênio na composição do GN é de aproximadamente $1 \%$, por isto, a remoção de nitrogênio à temperatura da obtenção de GNL antes de ser armazenado não é necessária, Remeljej (2005) também afirma que o fato de considerar um estágio de remoção de nitrogênio em qualquer processo conduziria à diminuição da eficiência global do processo em aproximadamente $1 \%$.

As condições de entrada do gás natural, saída do GNL e a temperatura dos pontos 3 e 4, são apresentados na Tabela 4.

Tabela 4- Condições da entrada do GN, saída do GNL e pontos 3 e 4.

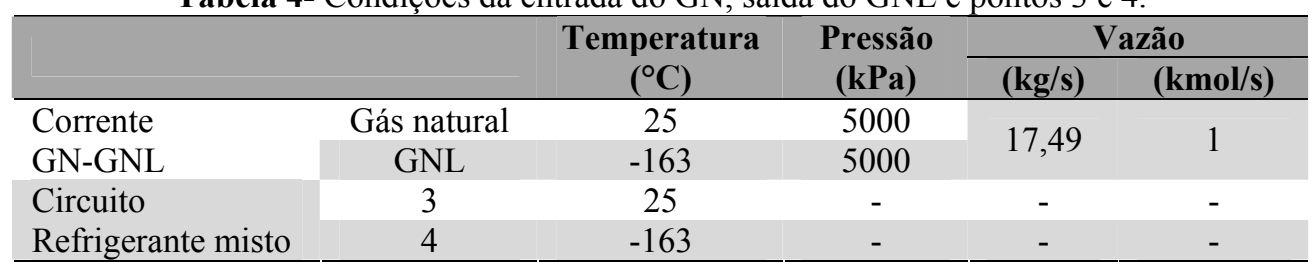


A taxa de produção do GNL é de 1511,4 t/d que corresponde a $17,5 \mathrm{~kg} / \mathrm{s}$ (vazão da corrente GN-GNL). Portanto é requerido um volume de $2064516 \mathrm{~m}^{3} / \mathrm{d}$ de gás natural a condições padrão de temperatura e pressão.

As seguintes condições e suposições são feitas:

- Os componentes do sistema de refrigeração usados no ciclo PRICO segundo os trabalhos de Lee e outros (2002) e Remeljej (2005) são: metano, etano, propano, butano e um gás não-condensável, nitrogênio.

- A eficiência isoentrópica do compressor é de 0,75 .

- Expansão através da válvula é isoentalpica.

- Queda de pressão no trocador de calor criogênico principal e no trocador intermediário considera-se desprezível.

A simulação inicia-se com o cálculo das propriedades da corrente do gás natural, com estes resultados gera-se a curva de resfriamento do gás natural. A curva do gás natural será utilizada para construir a curva composta quente para diferentes simulações realizadas no ciclo de refrigeração.

\section{RESULTADOS}

A avaliação do ciclo de refrigeração realiza-se controlando e ajustando parâmetros, como, os níveis de pressão, vazão e a composição da mistura de refrigerante no ciclo de refrigeração.

Nesta seção apresentam-se os resultados das simulações executadas na plataforma EES. A seqüência dos resultados inicia-se com a seleção da composição do refrigerante, mantendo fixas as variáveis da vazão e dos níveis de pressão no sistema de refrigeração. Após encontrar a melhor seleção da composição do refrigerante, mostram-se os resultados variando os níveis de pressão à vazão constante e, na parte final dos resultados, apresenta-se o efeito da variação da vazão do refrigerante.

Para a análise do sistema de refrigeração, valores da composição do refrigerante, vazão do refrigerante e níveis de pressão foram adotados da literatura técnica como pontos de partida. Segundo Lee e outros (2002), os parâmetros de simulação para processo PRICO são:

- Vazão do sistema de refrigeração de 3 a 4 vezes a vazão do gás natural.

- Pressão de condensação na faixa de $4000-5000 \mathrm{kPa}$.

- Pressão de evaporação na faixa de $400-500 \mathrm{kPa}$.

\subsection{ANÁLISE 1: SELEÇÃO DA COMPOSIÇÃO DO REFRIGERANTE}

Na seleção da composição dos refrigerantes, foram fixados os níveis de pressão e vazão do ciclo de refrigeração. Efetuaram-se uma serie de simulações com diferentes valores de pressão e vazão para obter resultados que garantissem a transferência de calor estabelecendo uma diferença mínima de temperatura. Escolheram-se 5 resultados com aproximadamente 1 grau de diferença mínima de temperatura, mostrados na Tabela 5.

Tabela 5 - Seleção da composição do refrigerante.

\begin{tabular}{|c|c|c|c|c|c|c|c|c|c|c|}
\hline \multirow[b]{2}{*}{ Caso } & \multicolumn{5}{|c|}{ Componentes } & \multicolumn{2}{|c|}{ Vazão } & \multirow{2}{*}{$\begin{array}{c}\text { Pressão } \\
\text { alta/baixa } \\
\text { (kPa) }\end{array}$} & \multirow{2}{*}{$\begin{array}{c}\text { Potência } \\
\text { do } \\
\text { compressor } \\
(\mathrm{kW})\end{array}$} & \multirow{2}{*}{$\begin{array}{c}\Delta \mathbf{T}_{\min } \\
\left({ }^{\circ} \mathbf{C}\right)\end{array}$} \\
\hline & $\mathbf{C}_{1}$ & $\mathbf{C}_{2}$ & $\mathbf{C}_{3}$ & $\mathrm{C}_{4}$ & $\mathbf{N}_{2}$ & $\mathrm{Kmol} / \mathrm{s}$ & $\mathbf{k g} / \mathbf{s}$ & & & \\
\hline 1 & 0,400 & 0,290 & 0,005 & 0,200 & 0,105 & 4,3 & 128,7 & $4900 / 300$ & 46105 & 0,98 \\
\hline 2 & 0,420 & 0,260 & 0,030 & 0,200 & 0,090 & 4,3 & 129 & & 460 & 1,03 \\
\hline 3 & 0,410 & 0,270 & 0,030 & 0,200 & 0,090 & 4,3 & 129,7 & $4900 / 300$ & 45973 & 1,00 \\
\hline 4 & 0,405 & 0,270 & 0,015 & 0,210 & 0,100 & 4,3 & 130,2 & $4900 / 300$ & 45406 & 0,97 \\
\hline 5 & 0,420 & 0,270 & 0,020 & 0,215 & 0,075 & 4,3 & 130,4 & $4900 / 300$ & 44852 & 0,98 \\
\hline
\end{tabular}

Os valores da pressão de alta, pressão de baixa e vazão do refrigerante observados na Tabela 5 são maiores que os parâmetros de simulação citados anteriormente por Lee e outros (2002). Isto se reflete no aumento da potência do compressor. Nota-se também que cada composição dos refrigerantes resulta em valores de potência de compressão diferentes, pois trocando a composição é possível alterar a forma da curva composta fria. 
Dos resultados mostrados, para uma vazão de $4,3 \mathrm{kmol} / \mathrm{s}$ e para uma pressão de condensação/evaporação de 4900/300 kPa respectivamente, a melhor seleção dos componentes do fluido refrigerante se dá no caso número 5. Com estes valores da composição obtém-se o menor requerimento de potência do compressor para uma diferença mínima de temperatura de $1{ }^{\circ} \mathrm{C}$, que é considerado muito pequeno para o projeto de trocadores de calor.

Através de modelos termodinâmicos obtiveram-se os resultados das curvas de cada caso representados em diagramas de temperatura-fluxo de entalpia, da Figura 10 até a Figura 14. As curvas indicadas são do resfriamento do gás natural, curva da corrente quente. As duas curvas, composta quente e composta fria, são resultados da combinação de interação entre as variáveis.

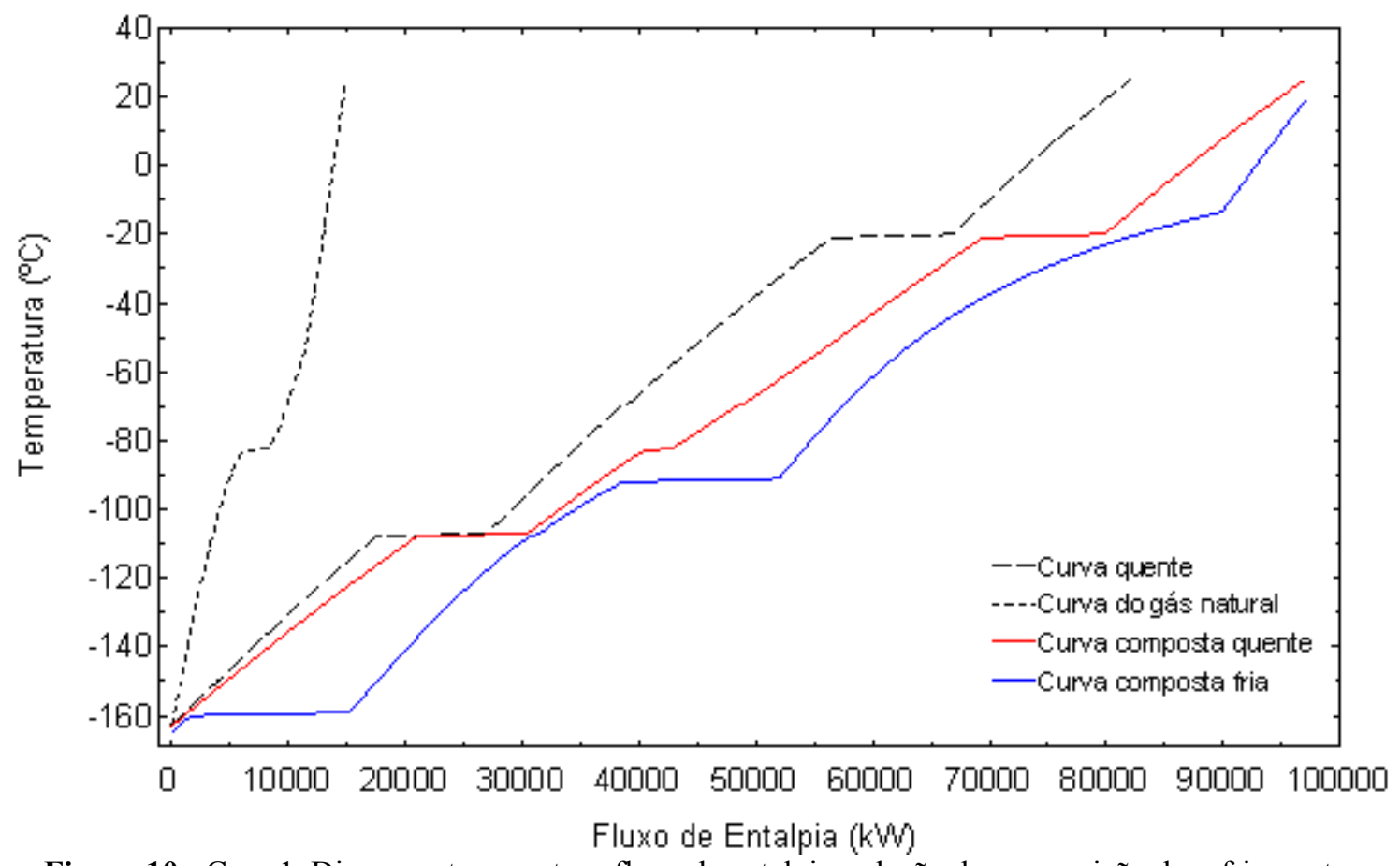

Figura 10 - Caso 1. Diagrama temperatura-fluxo de entalpia, seleção da composição do refrigerante.

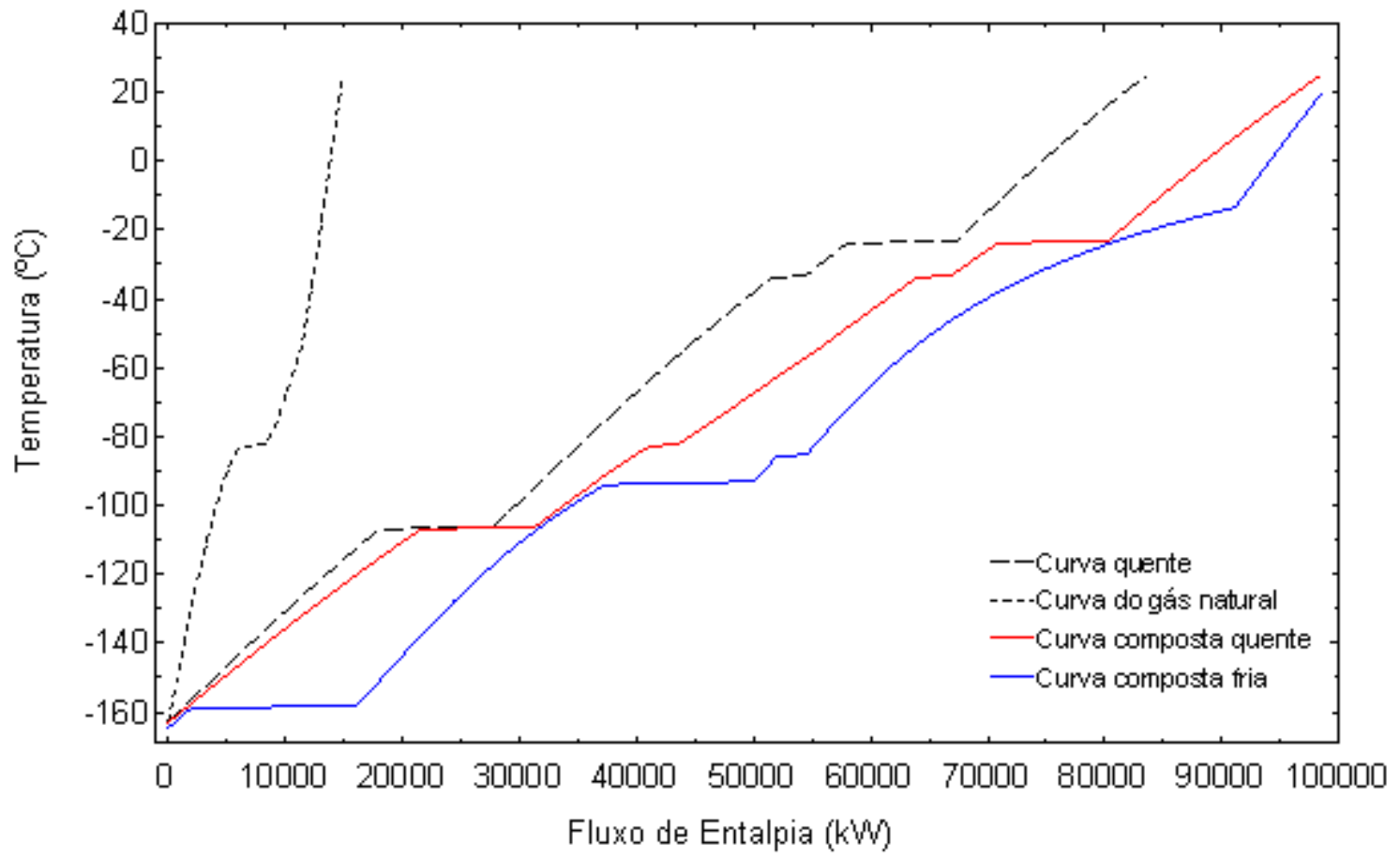

Figura 11 - Caso 2. Diagrama temperatura-fluxo de entalpia, seleção da composição do refrigerante. 


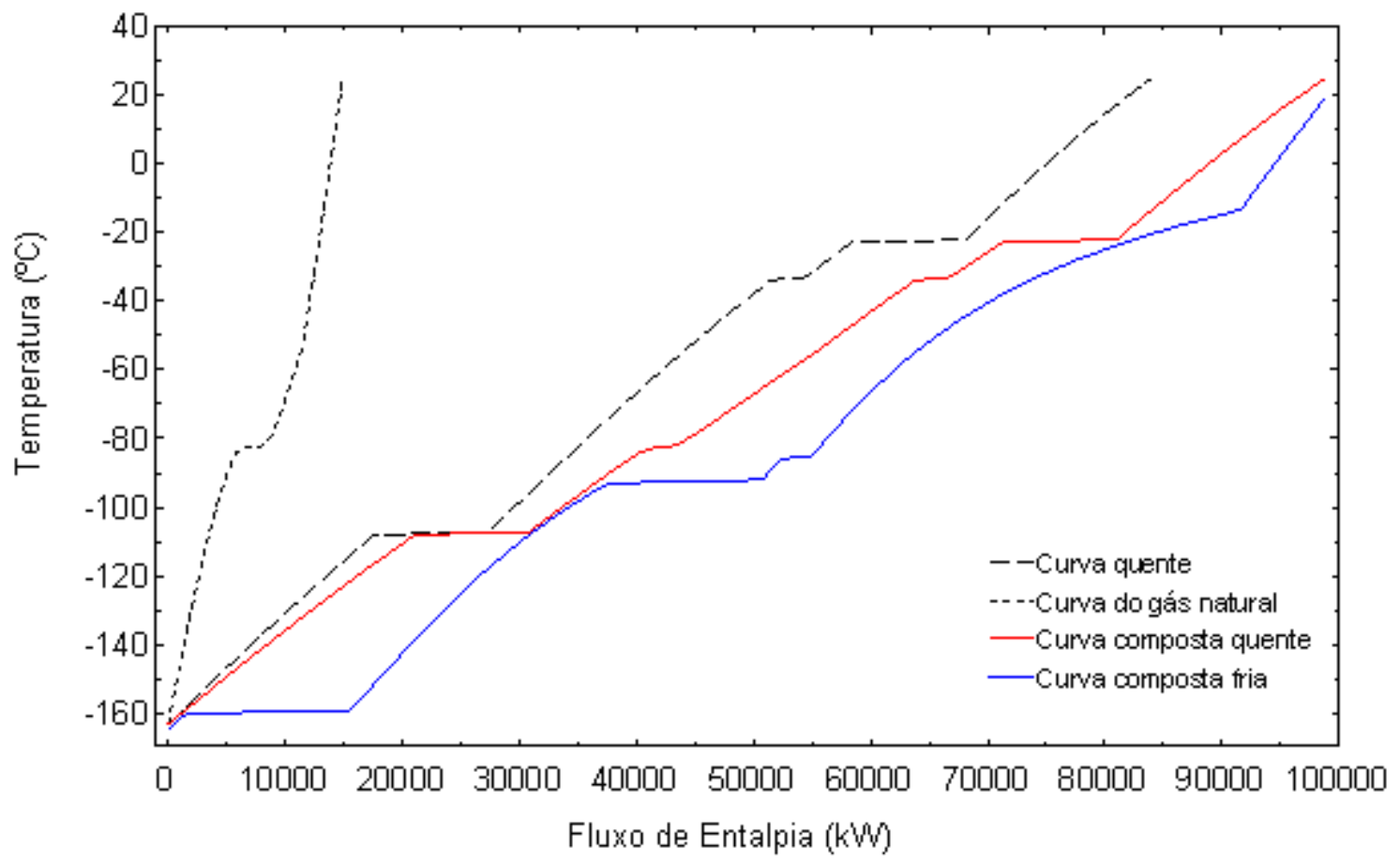

Figura 12 - Caso 3. Diagrama temperatura-fluxo de entalpia, seleção da composição do refrigerante.

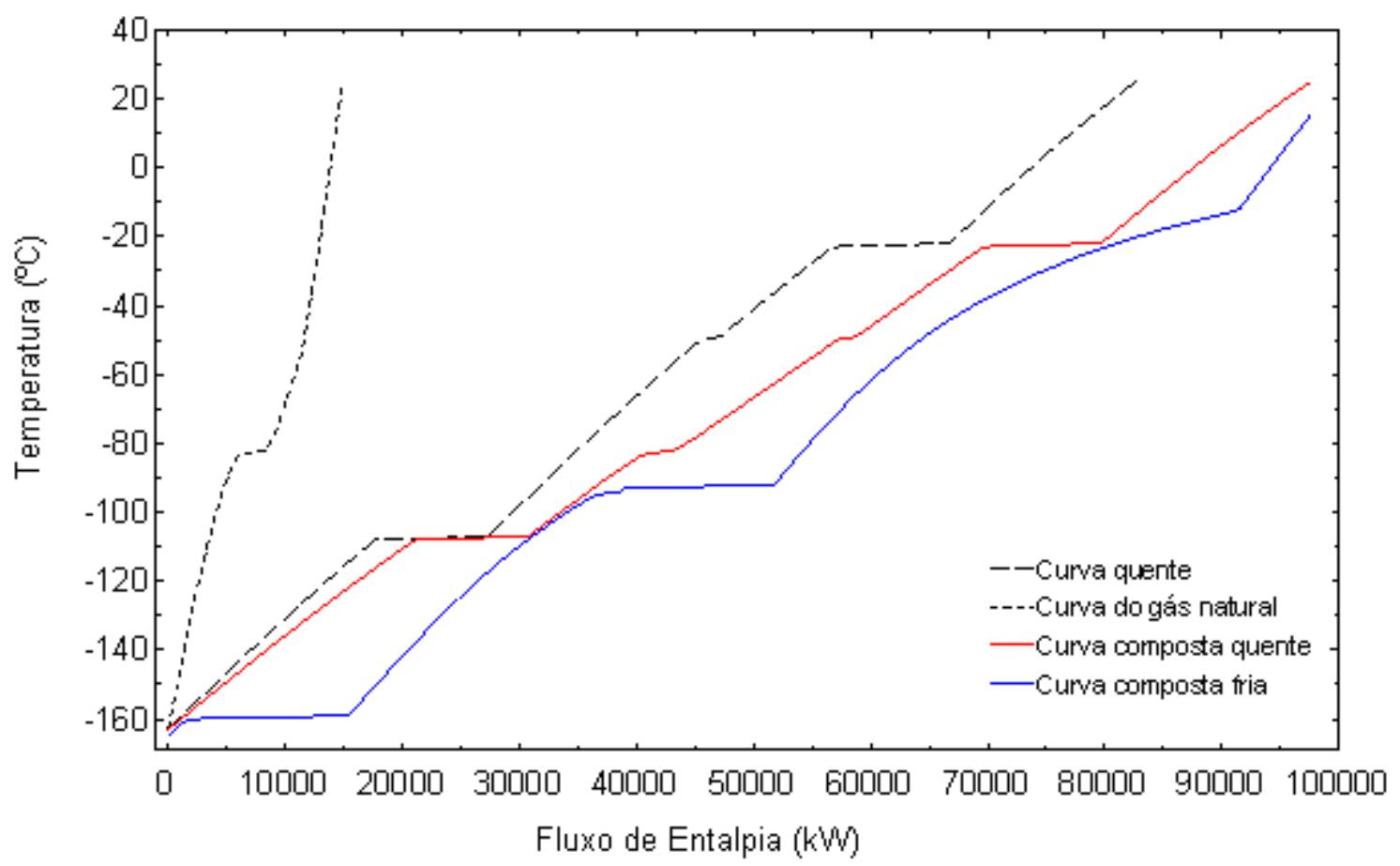

Figura 13 - Caso 4. Diagrama temperatura-fluxo de entalpia, seleção da composição do refrigerante.

Os resultados obtidos apontam a influência da composição do refrigerante nas curvas compostas para cada caso. Isto repercute na diferença de temperatura mínima em um ponto específico denominado ponto de pinça que permite prever a mínima área do trocador de calor.

Observa-se em cada figura que a soma da energia necessária para resfriar a corrente do gás natural e a corrente quente é igual à energia da curva composta fria. 


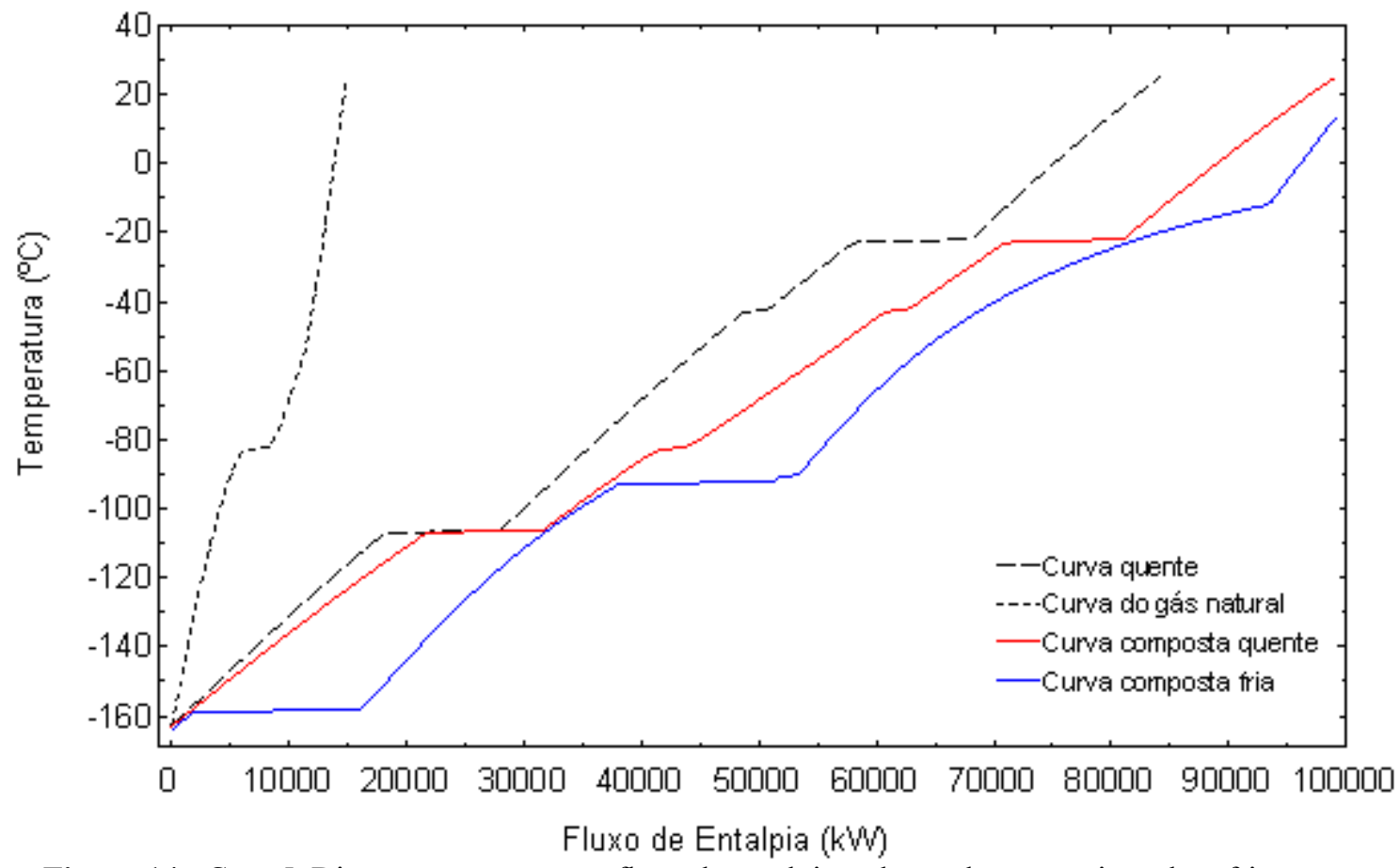

Figura 14 - Caso 5. Diagrama temperatura-fluxo de entalpia, seleção da composição do refrigerante.

\subsection{ANÁLISE 2: PRESSÃO DOS NIVEIS DO SISTEMA DE REFRIGERAÇÃO}

Para a análise do efeito da pressão no sistema de refrigeração mantiveram-se constante as variáveis de vazão e composição do refrigerante. Nas três primeiras simulações as pressões de condensação e evaporação foram modificadas mantendo constante a razão de pressão, após isto a razão foi aumentada.

Para efeito de comparação foram estudados cinco casos. Em cada caso adotou-se a correspondente composição do refrigerante da Tabela 5. Nos cinco casos estudados mantiveram-se fixa a vazão do refrigerante $(4,3 \mathrm{kmol} / \mathrm{s})$ como apresenta a Tabela 6 e Tabela 7.

Tabela 6 - Variação dos níveis da pressão.

\begin{tabular}{|c|c|c|c|c|c|c|c|}
\hline $\begin{array}{l}\text { Caso } \\
\text { de } \\
\text { estudo }\end{array}$ & $\begin{array}{c}\text { Pressão } \\
\text { Alta } \\
\text { (kPa) }\end{array}$ & $\begin{array}{c}\text { Pressão } \\
\text { Baixa } \\
\text { (kPa) }\end{array}$ & $\begin{array}{c}\text { Razão de } \\
\text { pressão }\end{array}$ & $\begin{array}{c}\text { Potência do } \\
\text { Compressor } \\
(\mathrm{kW})\end{array}$ & $\begin{array}{l}\text { Interseção } \\
\text { das curvas }\end{array}$ & $\begin{array}{c}\Delta \mathbf{T}_{\min } \\
\left({ }^{\circ} \mathrm{C}\right)\end{array}$ & $\begin{array}{l}\text { Localização do } \\
\text { ponto de pinça } \\
\left({ }^{\circ} \mathrm{C}\right)\end{array}$ \\
\hline \multirow{5}{*}{1} & 4500 & 300 & 15 & 44716 & Não & 0,43 & $-110,00 /-110,43$ \\
\hline & 4800 & 320 & 15 & 44591 & Não & 0,61 & $-108,12 /-108,73$ \\
\hline & 4900 & 326,5 & 15 & 44561 & Não & 0,69 & $-106,40 /-107,09$ \\
\hline & 4800 & 310 & 15,48 & 45169 & Não & 0,73 & $-108,02 /-108,75$ \\
\hline & 5000 & 270 & 18,52 & 48379 & Não & 1,91 & $-159,12 /-161,03$ \\
\hline \multirow{5}{*}{2} & 4500 & 300 & 15 & 44640 & Superior & --- & --- \\
\hline & 4800 & 320 & 15 & 44506 & Superior & --- & --- \\
\hline & 4900 & 326,5 & 15 & 44474 & Superior & --- & --- \\
\hline & 4800 & 310 & 15,48 & 45096 & Superior & --- & --- \\
\hline & 5000 & 270 & 18,52 & 48346 & Não & 1,65 & $-159,40 /-161,05$ \\
\hline \multirow{5}{*}{3} & 4500 & 300 & 15 & 44578 & Superior & --- & --- \\
\hline & 4800 & 320 & 15 & 44443 & Não & 0,03 & $-23,00 /-23,03$ \\
\hline & 4900 & 326,5 & 15 & 44409 & Não & 0,37 & $-22,00 /-22,37$ \\
\hline & 4800 & 310 & 15,48 & 45028 & Não & 0,56 & $-22,98 /-23,54$ \\
\hline & 5000 & 270 & 18,52 & 48275 & Não & 1,64 & $-159,60 /-161,24$ \\
\hline \multirow{5}{*}{4} & 4500 & 300 & 15 & 44032 & Superior & -- & --- \\
\hline & 4800 & 320 & 15 & 43906 & Superior & --- & --- \\
\hline & 4900 & 326,5 & 15 & 43875 & Não & 0,19 & $-21,90 /-22,09$ \\
\hline & 4800 & 310 & 15,48 & 44479 & Não & 0,32 & $-22,92 /-23,24$ \\
\hline & 5000 & 270 & 18,52 & 47660 & Não & 1,62 & $-106,00 /-107,62$ \\
\hline
\end{tabular}


Tabela 7 - Variação dos níveis da pressão.

\begin{tabular}{cccccccc}
\hline $\begin{array}{c}\text { Caso } \\
\text { de } \\
\text { estudo }\end{array}$ & $\begin{array}{c}\text { Pressão } \\
\text { Alta } \\
\mathbf{( k P a )}\end{array}$ & $\begin{array}{c}\text { Pressão } \\
\text { Baixa } \\
(\mathbf{k P a})\end{array}$ & $\begin{array}{c}\text { Razão de } \\
\text { pressão }\end{array}$ & $\begin{array}{c}\text { Potência do } \\
\mathbf{C o m p r e s s o r} \\
\mathbf{( k W )}\end{array}$ & $\begin{array}{c}\text { Interseção } \\
\text { das curvas }\end{array}$ & $\begin{array}{c}\Delta \mathbf{T}_{\text {min }} \\
\left({ }^{\circ} \mathbf{C}\right)\end{array}$ & $\begin{array}{c}\text { Localização do } \\
\text { ponto de pinça } \\
\left({ }^{\mathbf{0}} \mathbf{C}\right)\end{array}$ \\
\hline & 4500 & 300 & 15 & 43498 & Superior & --- & --- \\
5 & 4800 & 320 & 15 & 43337 & Superior & --- & --- \\
& 4900 & 326,5 & 15 & 43296 & Não & 0,88 & $-157,50 /-158,40$ \\
& 4800 & 310 & 15,48 & 43920 & Não & 0,30 & $-22,96 /-23,26$ \\
\hline & 5000 & 270 & 18,52 & 47134 & Não & 1,22 & $-159,79 /-161,01$
\end{tabular}

Analisando os resultados das três primeiras simulações para os cinco casos apresentados, onde a razão de pressão foi mantida fixa, observa-se que alterando a pressão do condensador e evaporador, obtêm-se diferentes valores da diferença mínima de temperatura variando, por sua vez, a localização do ponto de pinça com relação à temperatura devido ao afastamento das curvas composta quente e composta fria.

O afastamento entre as curvas composta quente e fria é diretamente proporcional ao incremento ou diminuição da diferença entre os dois níveis de pressão. A variação da pressão, seja no condensador ou evaporador, pode causar a interseção das curvas compostas. O aumento da razão de pressão evita a interseção das curvas composta quente e composta fria como mostram a Figura 15 e Figura 16.

Outro ponto a analisar é a forma das curvas compostas. Na Figura 15, os níveis de pressão são 4500/300 $\mathrm{kPa}$ e, na Figura 16, correspondem a 5000/270 kPa. Existe entre as duas simulações uma grande diferença de pressão e os resultados mostram que a forma das curvas compostas não tem mudança significativa, mas sim, o afastamento das curvas compostas (com relação à diferença de temperatura).

Os resultados da Tabela 6 e Tabela 7 mostram que os requerimentos da energia para a produção do gás natural liquefeito são sensíveis à diferença entre os dois níveis de pressão. Quanto maior for a razão de pressão maior será o requerimento de potência do compressor.

Segundo Lee e outros (2002), a alteração da pressão em qualquer um dos extremos do trocador de calor, frio ou quente, provoca aumento da diferença de temperatura entre as curvas composta quente e composta fria daquele extremo.

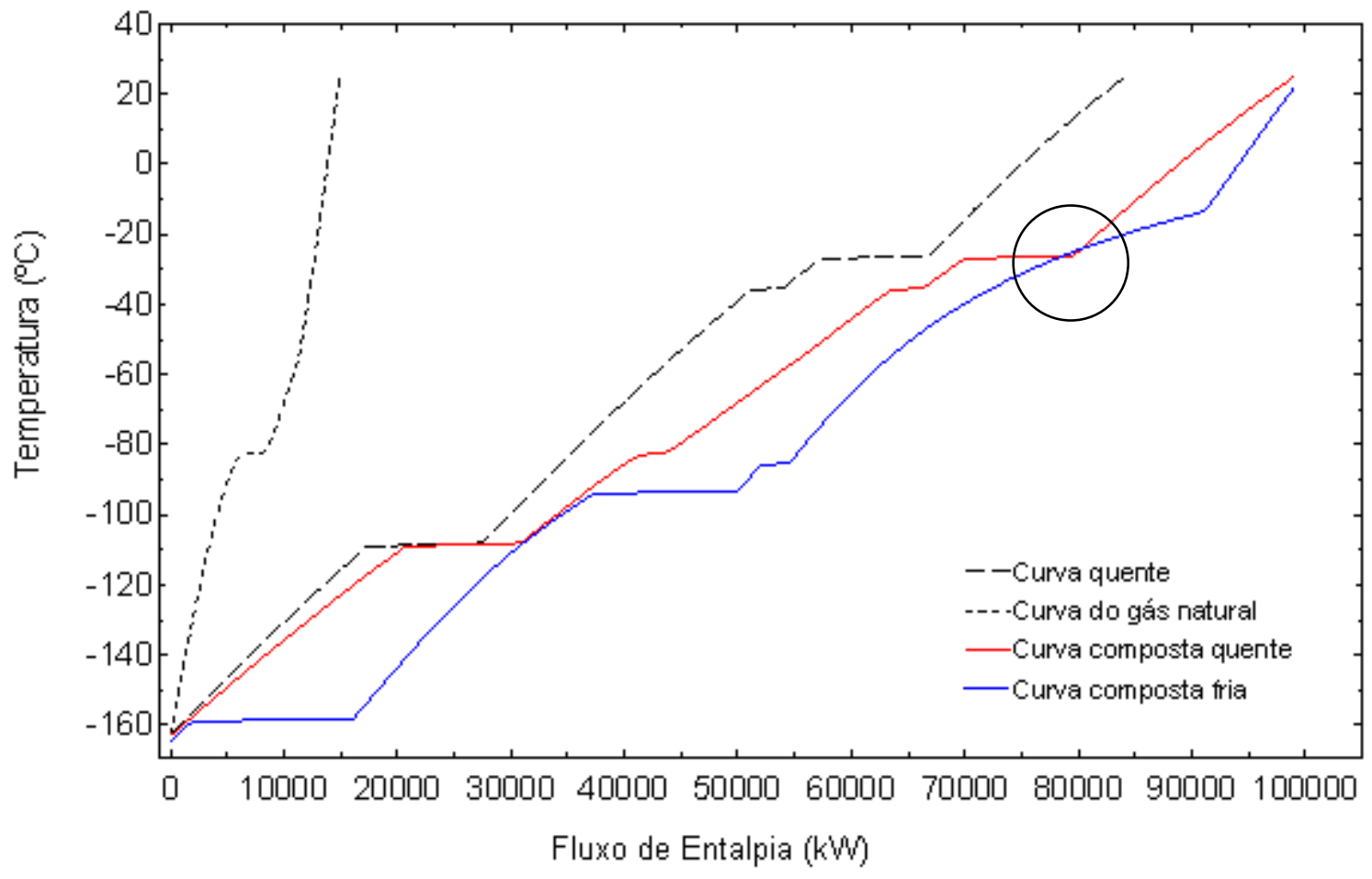


Figura 15 - Caso 2. Diagrama temperatura-fluxo de entalpia, níveis de pressão 4500/300 (kPa).

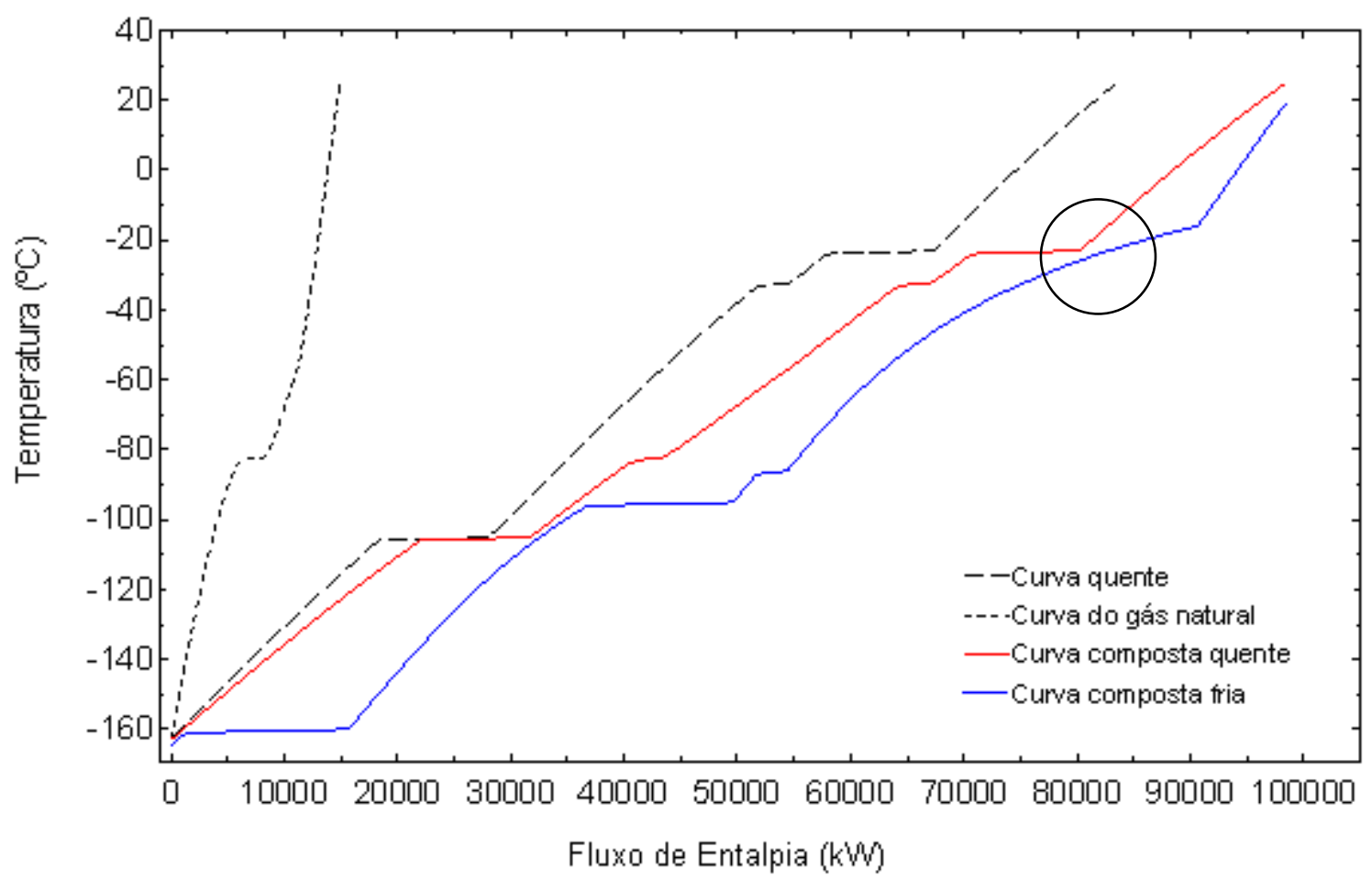

Figura 16 - Caso 2. Diagrama temperatura-fluxo de entalpia, níveis de pressão 5000/270 (kPa).

\subsection{ANÁLISE 3: VARIAÇÃO DA VAZÃO DO REFRIGERANTE}

Nesta seção, as simulações são realizadas fixando a composição do refrigerante que é mostrada na Tabela 5 , mantendo constantes os níveis de pressão em $5000 \mathrm{kPa}$ para a pressão de condensação e $270 \mathrm{kPa}$ para a pressão de evaporação. Estes valores dos níveis de pressão foram selecionados por serem os melhores resultados na variação da diferença dos níveis de pressão do sistema de refrigeração, já que, apresentam uma diferença mínima de temperatura aceitável para processos criogênicos, como mostra o resultado da Figura 16. Tem-se cinco estudos de caso para avaliação da vazão do refrigerante, mostrados na Tabela 8.

Tabela 8 - Variação da vazão do refrigerante.

\begin{tabular}{|c|c|c|c|c|c|c|}
\hline \multirow{2}{*}{$\begin{array}{l}\text { Caso de } \\
\text { estudo }\end{array}$} & \multicolumn{2}{|c|}{ Vazão } & \multirow{2}{*}{$\begin{array}{l}\text { Potência do } \\
\text { Compressor } \\
\text { (kW) }\end{array}$} & \multirow{2}{*}{$\begin{array}{c}\text { Transfe- } \\
\text { rência de } \\
\text { calor }(\mathbf{k W})\end{array}$} & \multirow{2}{*}{$\begin{array}{c}\Delta \mathbf{T}_{\min } \\
\left({ }^{\circ} \mathrm{C}\right)\end{array}$} & \multirow{2}{*}{$\begin{array}{c}\text { Localização do } \\
\text { ponto de pinça }\left({ }^{\circ} \mathrm{C}\right)\end{array}$} \\
\hline & $\mathrm{kmol} / \mathrm{s}$ & $\mathrm{kg} / \mathrm{s}$ & & & & \\
\hline \multirow{2}{*}{1} & 4,20 & 125,7 & 47487 & 95007 & 1,85 & $-106,97 /-108,82$ \\
\hline & 4,40 & 131,7 & 49272 & 98821 & 1,94 & $-159,11 /-161,05$ \\
\hline \multirow{2}{*}{2} & 4,20 & 126,1 & 47451 & 96860 & 1,60 & $-159,40 /-161,00$ \\
\hline & 4,40 & 132,1 & 49241 & 100341 & 1,68 & $-159,40 /-161,08$ \\
\hline \multirow{2}{*}{3} & 4,20 & 126,7 & 47380 & 96860 & 1,50 & $-105,98 /-107,48$ \\
\hline & 4,40 & 132,7 & 49168 & 100762 & 1,61 & $-159,41 /-161,02$ \\
\hline \multirow{2}{*}{4} & 4,20 & 127,5 & 46783 & 95574 & 1,40 & $-106,00 /-107,40$ \\
\hline & 4,40 & 133,3 & 48537 & 99415 & 1,83 & $-159,22 /-161,05$ \\
\hline \multirow{2}{*}{5} & 4,20 & 127,4 & 46267 & 97039 & 1,22 & $-159,83 /-161,05$ \\
\hline & 4,40 & 133,5 & 48000 & 100950 & 1,27 & $-159,80 /-161,07$ \\
\hline
\end{tabular}


Pelos resultados mostrados para os cinco casos, nota-se que o incremento da vazão do refrigerante provoca aumento da potência para o acionamento do compressor e aumento da taxa de transferência de calor necessária para resfriar o gás natural. O efeito do aumento da taxa de transferência de calor provoca deslocamento horizontal positivo nas curvas composta quente e composta fria. Pode-se notar este efeito comparando os diagramas temperatura-fluxo de entalpia da Figura 17 e Figura 18 com diferentes vazões.

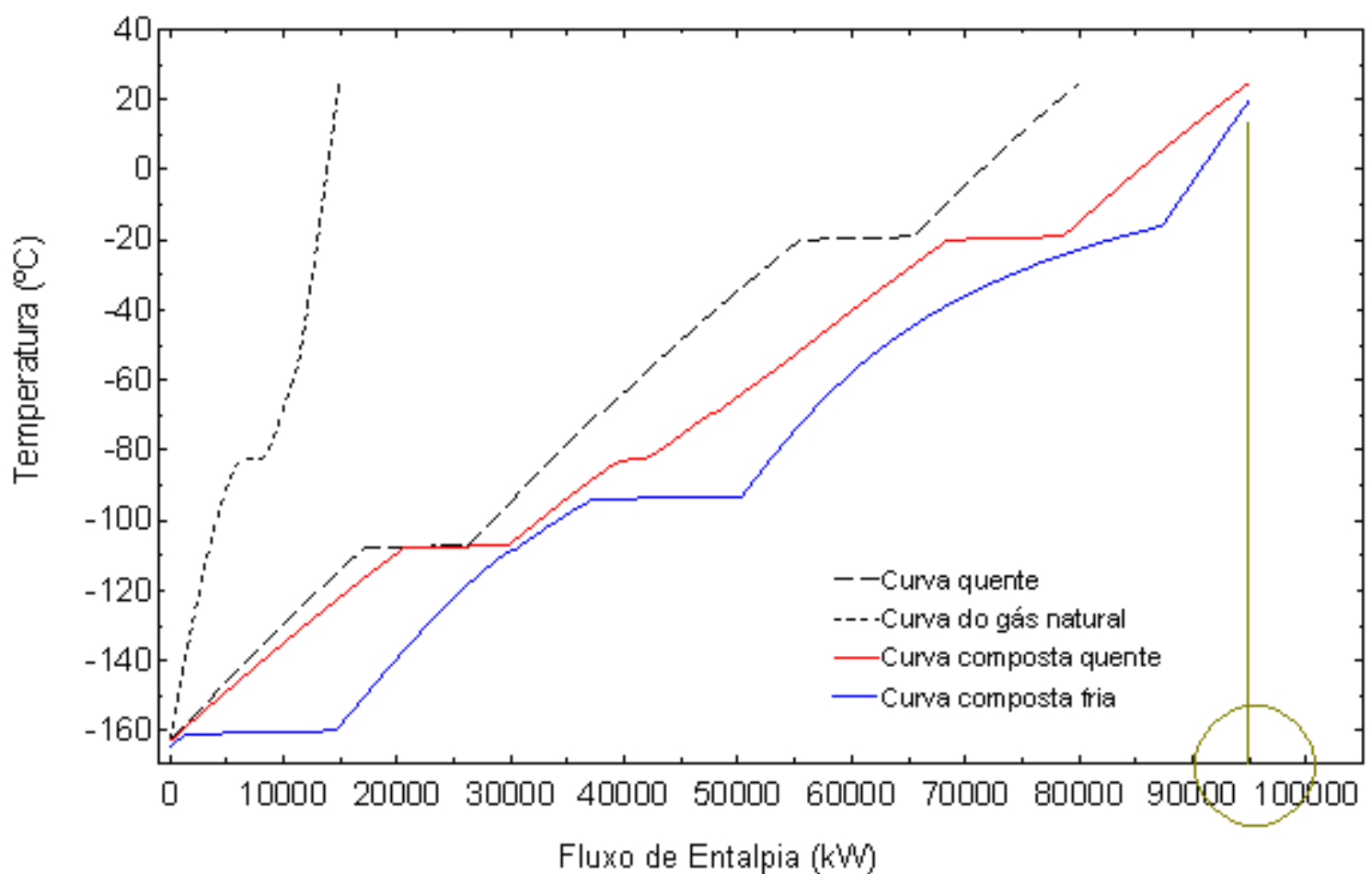

Figura 17 - Caso 1. Diagrama temperatura-fluxo de entalpia, vazão de 4,20 (kmol/s).

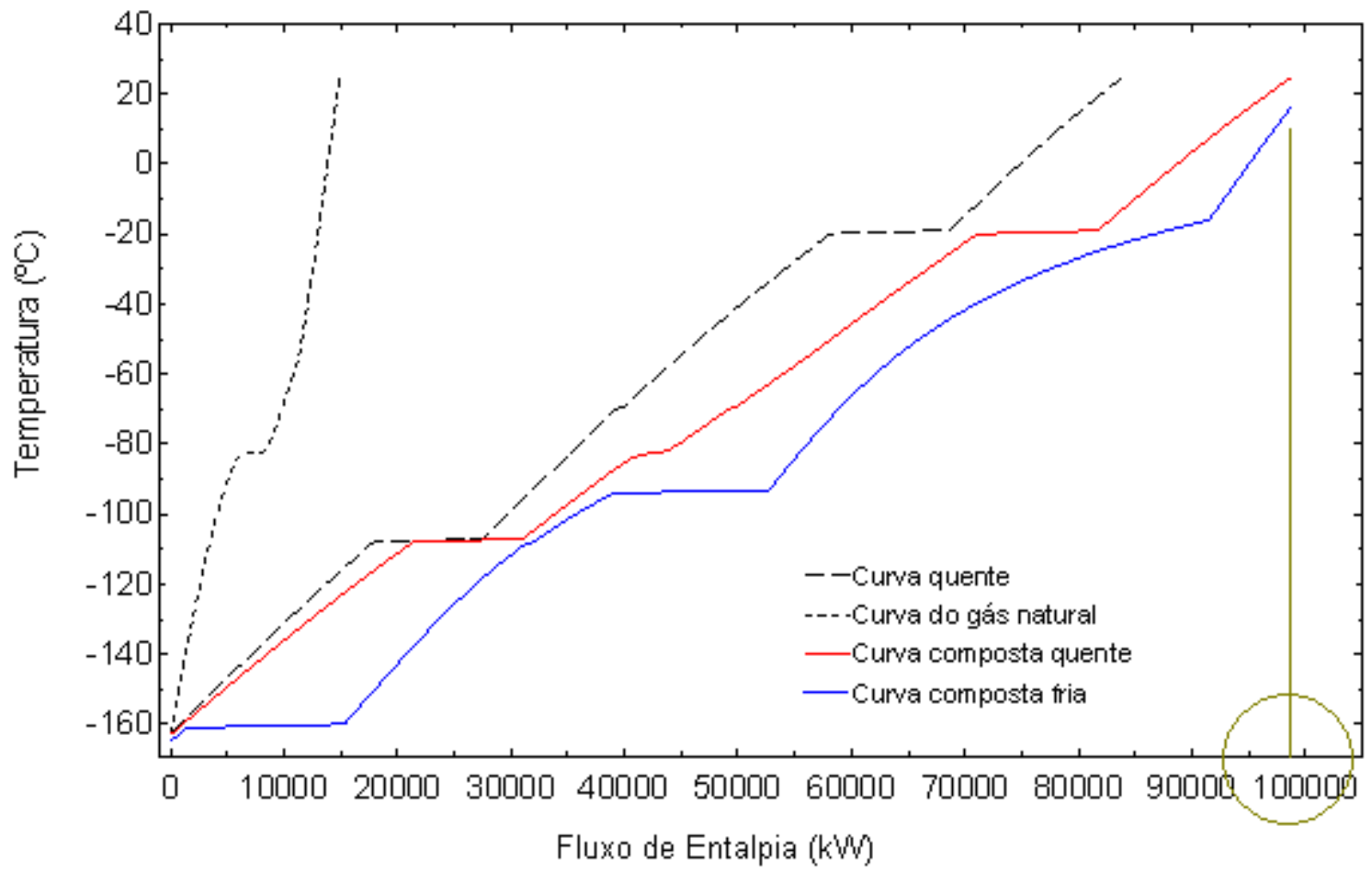

Figura 18 - Caso 1. Diagrama temperatura-fluxo de entalpia, vazão de 4,40 ( $\mathrm{kmol} / \mathrm{s})$. 


\section{DISCUSSÃO}

$>$ A aplicação dos modelos de gás e solução ideal influenciam nos resultados, já que ambos não consideram a interação entre as moléculas.

$>$ Apesar das limitações do modelo ideal usado, apresenta uma boa aproximação do comportamento real e permite, portanto, estabelecer um marco de comparação e um procedimento de análise.

$>$ É necessário otimizar o sistema de refrigeração para encontrar a melhor combinação da composição do fluido refrigerante misto, vazão do refrigerante e níveis de pressão, dado um valor mínimo aceitável de ponto de pinça, para melhorar a eficiência térmica do ciclo PRICO.

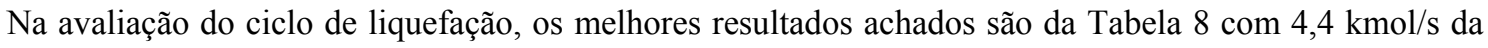
vazão do refrigerante e 5000/270 kPa da pressão de condensação e evaporação respectivamente, portanto:

$\checkmark$ Se for considerado a $\Delta T_{\min }$ visando um valor aceitável para o projeto de trocadores de calor aplicado ao processo criogênico, a melhor seleção da composição do refrigerante é do estudo de caso 1.

$\checkmark$ Se for considerado o menor consumo energético do compressor, a melhor seleção da composição do refrigerante é do estudo de caso 5.

Tabela 9 - Melhor composição do refrigerante misto.

\begin{tabular}{|c|c|c|c|c|c|c|c|c|c|c|}
\hline \multirow[b]{2}{*}{ Caso } & \multicolumn{5}{|c|}{ Componentes } & \multirow[b]{2}{*}{$\begin{array}{c}\text { Vazão } \\
(\mathrm{kmol} / \mathrm{s})\end{array}$} & \multirow{2}{*}{$\begin{array}{c}\text { Pressão } \\
\text { alta } \\
\text { (kPa) }\end{array}$} & \multirow{2}{*}{$\begin{array}{c}\text { Pressão } \\
\text { baixa } \\
\text { (kPa) }\end{array}$} & \multirow{2}{*}{$\begin{array}{c}\text { Potência } \\
\text { do } \\
\text { compressor } \\
\text { (kW) }\end{array}$} & \multirow[b]{2}{*}{$\begin{array}{c}\Delta \mathbf{T}_{\min } \\
\left({ }^{\circ} \mathbf{C}\right)\end{array}$} \\
\hline & $\mathrm{C}_{1}$ & $\mathrm{C}_{2}$ & $\mathbf{C}_{3}$ & $\mathrm{C}_{4}$ & $\mathbf{N}_{2}$ & & & & & \\
\hline 1 & 0,400 & 0,290 & 0,005 & 0,200 & 0,105 & 4,4 & 5000 & 270 & 49272 & 1,94 \\
\hline 5 & 0,420 & 0,270 & 0,020 & 0,215 & 0,075 & 4,4 & 5000 & 270 & 48000 & 1,27 \\
\hline
\end{tabular}

\section{CONCLUSÕES}

A análise dos resultados obtidos conduziu às seguintes conclusões principais:

$>$ Os requerimentos de potência para o acionamento do compressor são sensíveis à diferença dos níveis de pressão e à alteração da vazão do ciclo de refrigeração.

$>$ A modificação da composição do RM muda de forma significativa a forma das curvas composta quente e fria em comparação à alteração dos níveis de pressão e da vazão do ciclo refrigerante.

> São três os parâmetros fundamentais para a otimização do ciclo de refrigerante misto: composição da mistura refrigerante, níveis de pressão de condensação e evaporação, além da vazão da mistura refrigerante.

$>$ Existem diferentes proporções da composição do refrigerante para uma mesma $\Delta \mathrm{T}_{\min }$, mantendo constantes os níveis de pressão e vazão do ciclo de refrigeração.

$>$ Cada composição do refrigerante provoca diferentes resultados do requerimento de potência de compressão, segundo a forma das curvas composta quente e composta fria.

$>\mathrm{O}$ aumento dos níveis de pressão e da vazão do ciclo refrigerante, mantendo constante a composição do refrigerante, causa o incremento na $\Delta \mathrm{T}_{\min }$.

$>$ Uma grande diferença de temperatura reduz a eficiência do ciclo de refrigeração porque leva a maiores irreversibilidades. 
$>$ Partindo de dados de literatura, obteve-se as seguintes condições operacionais otimizadas:

a) Composição da mistura refrigerante: $40,0 \%$ de metano; $29,0 \%$ de etano; $0,5 \%$ de propano; $20,0 \%$ de butano e $10,5 \%$ de nitrogênio;

b) Pressão de condensação de $5000 \mathrm{kPa}$ e pressão de evaporação de $270 \mathrm{kPa}$;

c) Vazão mássica da mistura refrigerante de $131,7 \mathrm{~kg} / \mathrm{s}$.

Essa combinação de valores resultou em uma potência de compressão de $49272 \mathrm{~kW}$, temperatura de pinça de $1,9^{\circ} \mathrm{C}$ para produzir $1511,4 \mathrm{t} / \mathrm{d}$ de GNL.

\section{REFERÊNCIAS BIBLIOGRÁFICAS}

1. Canmet, Pinch Analysis: For the Efficient Use of Energy, Water \& Hydrogen. Energy Technology Centre, Natural Resources Canada, 2003.

2. Cascone, R., Advances in Small Scale LNG Technology Provide User Options, Oil \& Gas Journal, Vol. 2, p. 15, Abr-Jun. 2005;

3. Chart Industries, Liquefied Natural Gás, Disponível em: <http://www.chart-ind.com/index.cfm>. Acesso em: 20 Nov. 2007;

4. Conpet, Gás Natural - Informações Técnicas. Disponível em: <http://www.conpet. gov.br/comofazer/comofazer_int.php?segmento $=$ conpet\&id_comofazer_serie $=27>$. Acesso em: 18 Ago. 2008;

5. EIA, 2008. Glossary - Base Load Plant. Disponível em: <http://www.eia.doe. gov/glossary/glossary_b.htm>. Acesso em: Ago. 2008;

6. Finn, A. J., Johnson, G. L., Tomlinson T. R. Developments in natural gas liquefaction. hydrocarbon Processing, Gulf Publishing Co., Houston, vol. 78, No. 4, p. 47-59, Abr. 1999;

7. Foglietta, J. H.; Consider Dual Independent Expander Refrigeration for LNG Production, Hydrocarbon Processing, p. 39, 2004;

8. GTI. Development of a Small-Scale Natural Gas Liquefier, final report GTI project 65943, Gas Technology Institute. 2003;

9. Hamworthy Gas Systems, 2006, Small Scale \& Mini LNG Liquefaction System, Disponível em: $<$ http://www.hamworthy.com/products/products.asp? strareano $=27$ 3>. Acesso em: Nov. 2006;

10. Jensen, J. B., Skogestad, S. Optimal Operation of a Simple LNG Process. ADCHEM, International Symposium on Advanced Control of Chemical Processes. 2006;

11. Kirillov, N. G., Analysis of Modern Natural Gas Liquefaction Technologies. Chemical and Petroleum Engineering, vol. 40, No. 7-8, 2004;

12. Lee, G., Smith, R., Zhu, X, Optimal Synthesis of Mixed-Refrigerant Systems for Low-Temperature Process, Industrial \& Engineering Chemistry Research, vol. 41, p. 5016-5028. 2002;

13. Linnhoff, M., 1998, Introduction to Pinch Technology, UK. Disponível em: $<h t t p: / / w w w . k b c e n e r g y s e r v i c e s . c o m / d e f a u l t . e n e r g y . a s p ? i d=148>$. Acesso em: 15 Jan. 2008;

14. Mah R. S. H., Lin T. D., Part II. A Performance Evaluation Based on the simulation of a Natural Gas Liquefaction Process, AIChe Journal, vol. 24, Issue 5, p. 839-848. Abr. 1978;

15. Mokhatab, S., Wood, D., Breaking the Offshore LNG Stalemate, World Oil Magazine, vol. 228, No. 4, Abr. 2007;

16. Price, B. C. Small-scale LNG Facility Development, Black \& Veatch Pritchard Inc., Hydrocarbon Processing, vol. 82, No. 1, p. 37-39, Jan. 2003;

17. Remeljej, C. W.; Hoadley, A.F.A. An Exergy Analysis of Small-scale Liquefied Natural Gas (LNG) Liquefaction Processes. Elsevier. Energy, vol. 31, Issue 12, p. 2005-2019, Set. 2006;

18. Remeljej, C. W.; An Exergy Analysis of Small Scale LNG Process. Master minor thesis, Department of Chemical Engineering, Monash University, Melbourne, Australia, 2005;

19. Salof Companies, 2006, LNG Processes, Disponível em: <http://www.kryopak. com/kryopak_refrigeration_processes.php>. Acesso em: 10 Nov. 2006.

20. Shukri, T. LNG Technology Selection, Hydrocarbon Engineering. Fev. 2004.

21. Smith, J.M.; Van Ness, H.C.; Abbott, M.M., Introdução à Termodinâmica da Engenharia Química. McGraw-Hill, 2000. p. 697;

22. Tacuse, C., Simões-Moreira, J. R., Carvalho, E., Small-scale LNG Plant Technologies. Hydrocarbon World 2007. Touch Briefings. p. 28-33, 2007; 